\title{
A INSTITUIÇÃO DO ORÇAMENTO POR RESULTADOS: ASPECTOS INSTITUCIONAIS E A EXPERIÊNCIA INTERNACIONAL
}

\subsection{PRECONDIÇÕES PARA EFETIVIDADE DO ORÇAMENTO POR RESULTADOS}

\subsubsection{Motivação do setor público}

A instituição do orçamento por resultados, assim como qualquer reforma relacionada à estrutura do Estado e das atividades governamentais, demanda o envolvimento ativo de todo o plexo de atores, amparado na conscientização coletiva da necessidade da mudança e de que administração e orçamento por desempenho são de interesse de toda a sociedade, com fundamento no bem comum.

O consenso entre gestores públicos, bem como os colaboradores, sobre a importância da reforma em direção ao orçamento por resultados é vital para viabilizar sua implementação.

Por isso, os motivos para a utilização dos indicadores por desempenho devem ser identificados e ser claros, sob pena do modelo não seguir adiante e não perenizar na cultura estatal. Entre tais motivos encontram-se a maior pressão externa da população e dos próprios órgãos internos do governo para aprimorar 
a entrega de resultados, a fim de que os gastos dos recursos estatais sejam eficientes e eficazes ${ }^{1}$.

Jack Diamond retrata que, uma vez que a reforma orçamentária no sentido do orçamento por resultados é tomada com este consenso entre os diversos gestores e planejadores estatais, todos os setores da Administração Pública tornam-se, em certa medida, responsáveis por sua implementação nos mais diversos aspectos, conforme as suas respectivas competências e capacidades. Esse grau de comprometimento entre os órgãos governamentais permite mudanças nos procedimentos administrativos e fomenta a atitude das agências pela reformulação da administração orçamentária.

Sem que os setores da Administração Pública estejam motivados, qualquer mudança relacionada à busca por desempenho terá uma forte tendência a fracassar, tendo em vista a dificuldade inerente a essa espécie de medida e a falta da força necessária para engajar a mudança, ainda que seja incremental².

\subsubsection{Envolvimento conjunto dos Poderes Executivo e Legislativo}

Além disso, o orçamento por resultados clama por um envolvimento conjunto entre os Poderes, não bastando que se limite a uma iniciativa isolada do Poder Executivo - hipótese na qual o orçamento por resultados configuraria de fato mera técnica de gestão, como inclusive se verá adiante nas diversas acepções do “orçamento por resultados".

1 "Consensus among participants on the need for reform is critical to successful implementation. Public officials need to identify their motives for using performance measurement and performance budgeting. These motives may be external demands for service quality and accountability, as well as internal demands for efficiency and effectiveness (Wang 1999: 539). Public officials must also define the producers and consumers of performance-based information and provide an appropriate incentive strategy for that information's use. Finally, they must understand that performance-based information may be more helpful in improving management than in handling budgetary matters". SHAH, A.; SHEN C. Citizen-centric performance budgeting at the local level. In: SHAH, A. (Org.). Local budgeting. Washington D.C.: The International Bank for Reconstruction and Development/The World Bank, 2007, p. 162-164.

2 "Once the need for reform was recognized and accepted, a common approach is that it became part of the government's fiscal strategy, and a central element of government policy. The reform initiative was 'owned' and supported by all ministers, not just the ministry of finance (MOF) or the budget office. In this way, it formed a critical element of management strategy for all budget institutions. All public sector managers had to assume responsibility for its implementation, and this could not be left to those managing the agencies' budget or its accounting system. This high-level commitment facilitated the required changes in administrative procedures and the willingness of central agencies to devolve budget management". DIAMOND, J. Performance budgeting: managing the process. Washington D.C.: Fundo Monetário Internacional, 2003, p. 9. 
O ambiente político é crucial para o orçamento público e a decisão orçamentária é essencialmente política; de tal modo que não se pode cogitar de que a informação de desempenho será utilizada em processos decisórios sem que esteja associada ao elemento político para impulsioná-la.

Como bem afirma Anwar Shah, do Banco Mundial:

Forte e consistente suporte político do legislativo é crítico para as iniciativas de orçamento por resultados. Buscar racionalidade interna e critérios de eficiência sem considerar o ambiente político prejudicaria estas inciativas. Legisladores devem se envolver em estabelecer metas de desempenho, estabelecer indicadores de performance, monitorar o processo de desempenho, e avaliar os resultados de performance. É improvável o sucesso do orçamento por resultados se os setores executivo e legislativo tiverem diferentes ideias sobre a necessidade e os objetivos da reforma.

Nesse sentido, o êxito em incluir o desempenho da máquina pública como critério a ser considerado no processo orçamentário, a fim de implementar aspectos do orçamento por resultados, pressupõe um envolvimento político ativo, dependendo, eminentemente, de fatores administrativos e políticos preexistentes.

Dessa maneira, a reforma não se dá por uma tábula-rasa, tendo em vista que os sistemas legais já estão estabelecidos e consolidados na gestão estatal, inclusive quanto ao controle e à responsabilidade institucional dos atores envolvidos no processo orçamentário. Os indicadores e metas são introduzidos dentro dos sistemas existentes, bem como dos sistemas de controle e responsabilidade, considerando seus componentes formais e informais ${ }^{4}$.

Esses fatores são essenciais para qualquer reforma e não se pode desprezar em nenhum grau o aspecto político. A tarefa é árdua em conseguir envolver os diferentes poderes em torno de mudanças do sistema estabelecido, de sorte que a existência de alguma pressão - por parte da população, do atual desenvolvimento do país, ou de tensões no relacionamento entre os poderes - acaba por ser necessária para dar o pano de fundo unificador das propostas.

3 SHAH, A.; SHEN C. Citizen-centric performance budgeting at the local level. In: SHAH, A. (Org.). Local budgeting. Washington D.C.: The International Bank for Reconstruction and Development/The World Bank, 2007, p. 164-165.

4 "The successful use of the formalization of performance in the budgeting and management processes depends on other factors in the political and administrative environment of the country concerned. Reformers do not begin with a blank sheet; performance indicators and targets are introduced into existing and established systems of accountability and control, which have both informal and formal components." CURRISTINE, T. Governance performance: lessons and challenges. OECD Journal on Budgeting, Paris: OECD, v. 5, n. 1, 2005, p. 140. 
É a partir dessa linha de raciocínio que cabem críticas às iniciativas isoladas envolvendo o orçamento por resultados. O modelo já apresenta diversas complexidades inerentes e buscar a iniciativa de maneira isolada pode não ser uma sábia decisão.

O Poder Executivo de um Estado ou Município tentar lograr êxito sozinho em instituir o orçamento por resultados, apesar da louvável perspectiva da busca por resultados na gestão pública, pode conduzir a uma iniciativa fracassada e traumática no médio ou longo prazo, incapacitando ainda mais o cenário para mudanças.

Por isso, a pressão contrária de algum dos Poderes, em especial o Poder Legislativo, tendo em vista que sem o comprometimento do Poder Executivo dificilmente a iniciativa sairá do papel, dada a sutileza dos mecanismos do orçamento por resultados e a inexistência de regras jurídicas que o fundamentem e estimulem em um sistema ainda não preparado, conduzirá à derrocada do modelo e das reformas que se pretendia.

A dificuldade de permanência do orçamento por resultados (note-se, não se trata da tentativa de instituição, mas sim de manter e evoluir o sistema) é conhecida em âmbito internacional, sendo inclusive declarada pela OCDE.

Para viabilizar o orçamento por resultados, cabe ao direito financeiro instituir um ordenamento jurídico favorável que adote os princípios do modelo e permita a mudança, disciplinando aspectos como flexibilidade, incentivos, sanções, responsabilidade institucional e reclassificação dos programas orçamentários, além de instituir o princípio orçamentário de orientação por resultados.

Como bem retrata Allen Schick, um dos expoentes do tema desde a sua gênese, exceto em países em que o orçamento por resultados é previsto na legislação, o orçamento por resultados é provisório e sujeito a frequentes ajustes. Este é um dos problemas que pode ser identificado nas iniciativas brasileiras até então, inclusive na exemplar iniciativa do Estado de São Paulo, mais recentemente.

Segundo o autor, "mesmo quando a sua chegada é acompanhada de fanfarra política e aclamações autocongratulatórias, o orçamento por resultados parece estar perenemente em julgamento e incerto sobre sua permanência no poder"5. A existência de regras jurídicas constitutivas do sistema, portanto, é indispensável, clamando pela intervenção da ciência jurídica e do direito financeiro.

5 "Except in countries where it is prescribed by legislation, the installation PB often is provisional and subject to frequent adjustment. Even when its arrival is accompanied by political fanfare and self-congratulatory acclaim, PB appears to be perennially on trial and uncertain of its staying power." SCHICK, A. The metamorphosis in performance budgeting. In: 34th Annual Meeting of OECD senior budget officials. Paris: OECD, 2013, p. 5. 
Aliás, como ainda alerta Allen Schick ${ }^{6}$, no caso de substituição do governo ou caso novas reformas e modelos ganhem relevância, o modelo de orçamento por resultados tende a ser substituído por novas versões que, supostamente, podem trazer desempenhos ainda "melhores", desconsiderando as lições apreendidas no passado.

Assim, é arriscado lidar com iniciativas isoladas dos poderes, pois se torna fundamental um marco legal - daí o principal passo a ser dado no Poder Legislativo - que fundamente o sistema.

Eventuais reformas, rearranjos e reestruturações podem ser necessárias, como em qualquer experiência, mas a falta de envolvimento do Poder Legislativo, a inconstância de governos no Poder Executivo, e outros fatores político-institucionais podem levar ao fracasso das iniciativas logo no primeiro desafio a ser enfrentado.

Destarte, o envolvimento colaborativo entre os poderes constitui-se como precondição do orçamento por resultados, configurando terreno aberto para o jurista no direito financeiro. Eis que dificilmente as soluções nessa matéria poderão ser desenvolvidas nas ciências econômicas.

\subsubsection{Capacitação administrativa, tecnológica e contábil}

A capacitação dos setores administrativos é precondição técnica que diz respeito ao aspecto prático da instituição do modelo. Enquanto a motivação é condição essencial, o envolvimento dos Poderes é condição política, a capacitação administrativa, tecnológica e contábil do setor público é a condição técnica para que a instituição do orçamento por resultados seja viável.

O Banco Mundial é claro sobre essa exigência, afirmando que a história das reformas administrativas indica que o seu destino não depende dos conceitos teóricos, boas intenções e valores corretos, mas, sim, de questões operacionais: ou seja, como as pessoas resolverão problemas práticos e se elas conseguirão manter o suporte para sustentar o momentum da reforma.

\footnotetext{
6 "Even when its arrival is accompanied by political fanfare and self-congratulatory acclaim, PB appears to be perennially on trial and uncertain of its staying power. Whether because a new government is seated or new reforms become more fashionable, PB is likely to be replaced in due course by a later version, which rather than acknowledging its debt to previous performance-oriented initiatives stakes claim to be breaking virgin ground." SCHICK, A. The metamorphosis in performance budgeting. In: 34th Annual Meeting of OECD Senior Budget Officials. Paris: OECD, 2013, p. 5.
} 
Conforme ressaltam Shah e Shen ${ }^{7}$, em vez de instituir um sistema para todos os programas seguirem, a reforma deve respeitar diferenças institucionais entre as entidades, auxiliando-as a desenvolver abordagens que se adequem à peculiaridade das situações e ao contexto existente. Para que tal abordagem tenha sucesso, deve-se fornecer às entidades informações úteis para analisar o impacto do que elas estão fazendo e identificar como esta informação as auxilia em planejar.

Segundo os autores, "a construção da capacidade administrativa - pessoal, sistemas de informação, princípios de contabilidade, e mais importante, potencial de financiamento - está altamente associada com o uso de medidas de desempenho no orçamento" .

Por essas razões, Robinson alerta que a implementação do orçamento por resultados não é uma reforma na gestão pública apropriada para todos os países, porquanto os aprimoramentos técnicos exigidos pelo modelo exigem qualidade na governança do setor público. Sem desenvolver capacidades básicas de administração, tecnologia e contabilidade no âmbito da Administração Pública, não se pode esperar o êxito de reformas dessa envergadura.

Nas palavras do autor, "aprimoramentos técnicos como o orçamento por resultados não podem criar expectativa de sucesso em melhorar a eficiência e efetividade do gasto público em países com governança muito pobre”.

Se, por exemplo, a liderança política e burocrática for altamente corrupta, sem efetivo interesse em estimular o desempenho do setor público, o orçamento por resultados e outras iniciativas da administração por resultados, os esforços serão um desperdício?.

7 SHAH, A.; SHEN C. Citizen-centric performance budgeting at the local level. In: SHAH, A. (Org.). Local budgeting. Washington D.C.: The International Bank for Reconstruction and Development/The World Bank, 2007, p. 165-166.

8 Ibidem. "Building of administrative capacity—personnel, information systems, accounting standards, and most important, funding potential-is highly associated with the use of performance measurement in budgeting".

9 "Performance-based budgeting is not, as noted above, an initiative that is appropriate for all countries. A decision about whether to introduce such a system in any specific country should be based on sober consideration of the governance conditions, the state of the basic public financial management (PFM) systems, and the available human and financial resources.

Technical improvements like performance-based budgeting cannot be expected to succeed in improving the efficiency and effectiveness of public expenditure in countries with very poor governance. If, for example, the political and bureaucratic leadership is highly corrupt and rent-seeking, with little interest in improving public sector performance, performance-based budgeting and other 'managing-for-results initiatives' will be a waste of effort.” ROBINSON, M.; 
A capacidade administrativa e de gestão financeira configura, consoante, requisito essencial. Jack Diamond também traz à tona a questão, especialmente quanto à capacidade de gestão financeira e contabilidade, afirmando que o orçamento por resultados deve estar alicerçado em uma plataforma consistente de gestão das instituições governamentais, enfatizando aí três áreas ${ }^{10}$ : (i) sistema de controle interno dentro das instituições orçamentárias; (ii) mecanismos para suprimir as volumosas demandas por informação, inclusive em referência ao desempenho das atividades estatais; e (iii) custeamento suficiente para todos os programas e atividades governamentais.

Por fim, há a condição tecnológica igualmente fundamental à instituição prática do orçamento por resultados. O modelo requer um conjunto denso e detalhado de informações sobre o desempenho das atividades governamentais, de sorte que uma plataforma sólida para processar essa base de dados torna-se indispensável. Os gestores públicos precisam dispor de ferramentais tecnológicas para serem capazes de obter e inserir as informações de desempenho nas decisões de gasto na Administração Pública.

Diamond esclarece que a administração do orçamento por resultados deve ser baseada em uma plataforma apta de tecnologia da informação, englobando em um aspecto geral o software para auxiliar na formulação do orçamento, execução e operações de contabilidade ${ }^{11}$.

LAST, D. A basic model of performance-based budgeting. Washington: Fundo Monetário Internacional - Departamento Fiscal, 2009, p. 8.

10 "There has been increasing recognition that PB reforms should be based on a solid financial management platform within government institutions. This 'micro basis' or wider budget system reforms is easy to take for granted, but is problematic if neglected. In particular three areas have been adequately emphasized: the internal control systems in budget institutions; mechanisms to meet the heavier demands for information, particularly of a performance nature; and the need for full costing all government activities and programs." DIAMOND, J. Challenges to implementation. In: ROBINSON, M. (Org.). Performance budgeting: linking funding and results. Basingstoke: Fundo Monetário Internacional/Palgrave Macmillan, 2007, p. 381.

11 "Clearly PB is a heavy user of information. Detailed and robust financial information is demanded of managers to adequately track the costs of their operations, and at the same time additional performance information is required to relate these costs to their outputs and outcomes. In turn this implies PB management should be based on a firm IT platform. At its most general this will include software to assist in budget formulation, budget execution, and accounting operations.” DIAMOND, J. Challenges to implementation. In: ROBINSON, M. (Org.). Performance budgeting: linking funding and results. Basingstoke: Fundo Monetário Internacional/Palgrave Macmillan, 2007, p. 381. 


\subsection{ADMINISTRAÇÃO PÚBLICA POR RESULTADOS}

\subsubsection{A mudança de paradigma da Administração Pública}

O Estado contemporâneo tem por objetivo a instituição e garantia dos direitos estabelecidos no programa constitucional e a prestação dos serviços governamentais com máxima efetividade, a pretexto de conduzir a marcha evolutiva da sociedade rumo à proteção dos direitos humanos em todas as suas dimensões, inclusive nas dimensões futuras que surgirão ao longo do tempo.

O aparato burocrático, com suas ineficiências, já não se compatibiliza com as exigências das democracias modernas. O novo paradigma da Administração Pública é a eficiência, elevada ao patamar de princípio constitucional, conforme a regra inscrita no art. 37 da Constituição Federal, e que deve ser o norte da atividade governamental.

Como bem ensina Allen Schick, a nação estado contemporânea existe para desempenhar, para "prestar assistência financeira, serviços públicos e outros benefícios para a população". De tal sorte, o desempenho do governo influencia diretamente no bem-estar econômico e social dos cidadãos, nos programas e comportamentos de políticos e burocratas, e no relacionamento entre governantes e governados ${ }^{12}$.

O setor público não apenas atua em uma gama maior de funções do que anteriormente, como, também, é responsável por um grupo de obrigações muito mais heterogêneo que em períodos anteriores. A Administração Pública voltada ao desempenho, aos resultados, é essencialmente parte de um Estado em movimento de transição, adaptando-se a uma realidade social inédita, com o fim de reformar suas estruturas para acompanhar as novas restrições e oportunidades impostas.

O desempenho, nesse aspecto, não é um indicador estático, mas dinâmico, que requer uma constante avaliação e monitoramento dos resultados e impactos das políticas públicas por parte do Estado a fim de que este seja capaz de policiar e dosar de forma mais consciente as suas atividades.

Nessa questão, aliás, vale trazer a lição de Regis de Oliveira:

O Estado ideal não existe. Nem em tamanho, nem em população, nem em forma de governo. As situações são fluidas e, pois não há que se idealizar as

12 SCHICK, A. The performing State: reflection on an idea whose time has come but whose implementation has not'. OECD Journal on Budgeting, Paris: OECD, v. 3, n. 2, 2003, p. 72. 
coisas. Estas são móveis e se submetem a uma série infindável de alterações. Logo, não se pode criar um Estado ideal e muito menos um governo ideal ${ }^{13}$.

O orçamento por resultados não é iniciativa isolada e está dentro do prisma mais amplo de reformas administrativas do Estado que vêm sendo instituídas para aprimorar o desempenho da atividade governamental. Esse movimento ficou conhecido como performance management ou Administração Pública por resultados e tem por escopo a introdução de diversas medidas que reformulam a estrutura da Administração Pública para que seja orientada pela entrega otimizada de resultados concretos nos serviços públicos e nas atividades estatais, em benefício da população e em harmonia com o programa jurídico estabelecido para a instituição dos direitos.

Essas reformas incluem as mudanças no serviço público ${ }^{14}$ projetadas para estimular a motivação e os incentivos aos servidores públicos, que, muitas vezes, encontram desmotivação na falta de perspectiva de crescimento e nas amarras do ambiente burocrático que impedem a realização de seus objetivos sociais gratificantes.

Abrangem, igualmente, a restruturação organizacional para aperfeiçoar a entrega de serviços públicos, como já dito, e assim avançar na coordenação entre as diversas atividades do governo - cite-se como exemplo, nesse ponto, a criação de agências e redução do número de ministérios. Não se procura descartar a estrutura do Estado, mas sim recriá-la à luz de uma arquitetura institucional que leve o cidadão para o centro da atividade governamental como destinatário final dos resultados dos serviços públicos e titular último dos direitos fundamentais e sociais sob a responsabilidade do Estado.

Além disso, a administração por resultados encampa mudanças institucionais e nos mecanismos de monitoramento e supervisão com o intuito de fortalecer a responsabilidade institucional pública pelo desempenho. Busca-se dar responsabilidade pelos resultados atingidos, tendo em vista o planejamento apresentado pelo governo, supervisionando e responsabilizando (a princípio, por meio de incentivos) com base na performance, nos produtos, resultados e impactos revelados pelas ações tomadas, dirimindo o controle de meios.

Isso se pauta na melhora substancial da eficiência e efetividade do gasto público, na administração efetiva e na melhora constante do serviço público. O uso

13 OLIVEIRA, Regis Fernandes. Indagação sobre os limites da ação do Estado. São Paulo: RT, 2015, p. 165.

14 Nesse sentido: ROBINSON, M.; LAST, D. A basic model of performance-based budgeting. Washington: Fundo Monetário Internacional - Departamento Fiscal, 2009, p. 2. 
responsável dos recursos está umbilicalmente ligado à forma de administração, e, assim, o direito financeiro é simbiótico com o direito administrativo para que os avanços tornem-se possíveis, trazendo um grande leque de temas para a discussão, pesquisa e constante reflexão a respeito dos métodos em vigor e do sistema que se procura atingir. A busca é pela máxima eficácia e efetividade do desempenho governamental dirigido a atingir os objetivos desenvolvimentistas elencados no programa constitucional de direitos.

No Brasil, é preciso destacar o principal plano elaborado até então, o "Plano Bresser Pereira" ou "Plano Diretor da Reforma do Aparelho do Estado". Tal plano buscou reformar a Administração Pública com base nos critérios da administração gerencial, superando o paradigma burocrático weberiano. O plano teve sucesso em vários aspectos e instituiu uma legislação mais atualizada e em consonância com os conceitos modernos apresentados, mas ainda assim não logrou uma transformação cultural e estatal apta a erradicar o regime burocrático com a introdução da administração por resultados ${ }^{15}$.

Conforme retrata o então ministro autor da reforma:

O objetivo geral da reforma administrativa será transitar de uma Administração Pública burocrática para a gerencial. Essa mudança, porém, não pode ser realizada de um dia para o outro. Nem deve ocorrer com a mesma intensidade nos diversos setores. Na verdade, a Administração Pública gerencial deve ser construída sobre a Administração Pública burocrática. Não se trata de fazer tábula rasa desta, mas de aproveitar suas conquistas, os aspectos positivos que ela contém, ao mesmo tempo que se vai eliminando o que já não serve $e^{16}$.

15 Sobre o Plano Bresser Pereira, Regis Fernandes de Oliveira narra que: "O plano teve começo, meio e fim e buscava modernizar o Estado e iria da administração patrimonialista para a burocrática e terminaria no que se objetivava que era a Administração Pública gerencial. No primeiro caso, o aparelho do Estado funciona nas mãos do soberano. Manda e dispõe dele como lhe aprouver. No segundo caso, criam-se princípios orientadores da burocracia, tais como a carreira, a hierarquia, a impessoalidade e o formalismo que caracteriza o poder racional-legal. Foi bem analisado por Max Weber em 'Sociedade e Estado'. Na terceira hipótese, a administração busca definição de objetivos, preferencialmente dos recursos humanos, materiais e financeiros e institui mecanismos de controle". OLIVEIRA, Regis Fernandes de. Orçamento de resultado ou de desempenho. Revista Fórum de Direito financeiro e Econômico - RFDFE, Belo Horizonte, ano 3, n. 5, mar./ago. 2014, p. 13-14.

16 PEREIRA, Luiz Carlos Bresser. Da Administração Pública burocrática à gerencial. In: PEREIRA, Luiz Carlos Bresser; SPINK, Peter (Org.). Reforma do Estado e Administração Pública. 7. ed. Rio de Janeiro: Editora FGV, 2006, p. 264. 


\subsubsection{Cultura institucional de produtividade e a cultura burocrática}

Nesse novo paradigma da Administração Pública, busca-se a construção de uma cultura institucional de produtividade, que contraste com a cultura burocrática weberiana com ênfase no controle dos meios. Na nova visão da Administração Pública por resultados, mitiga-se as prioridades burocráticas de formalismo e hierarquia de um lado, concedendo-se maior flexibilidade na organização das atividades, com intuito de encontrar as formas mais eficientes de atingir os resultados esperados.

Com efeito, no modelo burocrático-tradicional de Administração Pública pretende-se a eficiência por meio do cumprimento de regras e regulações estabelecidas, controlando recursos e insumos, de maneira a aderir aos "dogmas" do setor público.

Todavia, como assevera Curristine, esse sistema funcionou bem em geral quando as tarefas dos governos eram menos complexas e mais padronizadas e enquanto o cumprimento das normas era considerado mais importante do que a eficiência e a efetividade. Nesse sentido:

O sistema foi criticado, entretanto, porque funcionários tendem a tornar-se mais focados em processos do que resultados, e haviam fracos incentivos para utilizar recursos eficientemente para atingir objetivos. Administradores públicos modernos não somente tem que servir interesses coletivos de justiça e probidade, mas também tem que atender necessidades individuais e endereçar problemas sociais complexos ${ }^{17}$.

Nessa esteira, é evidente que os sistemas tradicionais de Administração Pública não se compatibilizam com a flexibilidade e capacidade de adaptação essenciais à sociedade moderna com serviços personalizados. Essa necessidade incrementa a pressão pela eficiência e passa a exigir o crescente uso de agentes privados, como em contratos de concessão ou com entidades do terceiro setor.

Urge-se buscar incentivos de desempenho que já não se harmonizam com o ambiente burocrático. A população cansa-se do enfoque em processos, tornando-se mais exigente, clamando por resultados. O desperdício de verbas públicas é enxergado em contraste com os resultados que poderiam ter sido atingidos, deixando a sociedade perplexa com a ineficiência governamental.

17 "The system has been criticized, however, because employees tended to become more focused on process than on results, and there were weak incentives to use funds efficiently to achieve objectives." CURRISTINE, T. Governance performance: lessons and challenges. OECD Journal on Budgeting, Paris: OECD, v. 5, n. 1, 2005, p. 129. 
Daí o desafio do Estado contemporâneo que não se restringe ao paradigma weberiano de ter um Estado racional, formal, orientado por meios; mas um Estado produtivo, cuja prioridade seja a realização de resultados, a efetivação de direitos e a entrega de serviços em benefício dos cidadãos, titulares jurídicos finalísticos dos bens, serviços e políticas públicas.

$\mathrm{Na}$ perspectiva orçamentária, Carlos Fonrouge já descrevia a burocracia como um dos problemas centrais para o crescimento do gasto público, em especial ao se considerar a captura de grupos ou setores no orçamento. $\mathrm{O}$ modelo burocrático, diante da falta de critérios qualitativos, apresenta a tendência de satisfação de interesses particulares em detrimento dos interesses do Estado ${ }^{18}$.

Ouda, por sua vez, relata como principais críticas econômicas ao modelo burocrático de Administração Pública a falta de incentivos para administrar os recursos públicos de maneira eficiente e efetiva, e o foco em insumos (inputs) ao invés de outputs (produtos-resultados). Não há um relacionamento entre insumos e resultados, os administrados não são responsáveis por seus departamentos, o gasto é mais importante que os custos, não há avaliação de desempenho, entre outros fatores. Ademais:

Administradores podem não ter sido expostos a técnicas modernas de administração e seguem métodos baseados em precedentes ao invés de iniciativa pessoal. Ministérios tomam decisões detalhadas sobre a administração de departamentos sem ter informação e conhecimento adequados. Adicionalmente, administradores agem como uma extensão do Ministério, sem ter qualquer existência independente e consequentemente nenhuma responsabilidade independente ${ }^{19}$.

No âmbito da OCDE, do ponto de vista orçamentário, essa abordagem tem se dado com a concessão de maior discrição aos ministérios e administradores

18 "Burocracia y presión política: Es posible mencionar, finalmente, causas morbosas pero reales, como una tendencia a la empleomanía, determinante del crecimiento de la burocracia administrativa, y la presión de grupos o sectores con influencia política que tienden a satisfacer sus intereses particulares a costa del presupuesto del Estado”. FONROUGE, Carlos M. Giuliani. Derecho financiero. Buenos Aires: Depalma, v. I, p. 178.

19 OUDA, H. A. G. Suggested framework for implementation of performance budgeting in the public sector of developing countries with special focus on Egypt. Gante: 13th Biennial CIGAR Conference, 2011, p. 7. Observe-se, ainda, que: "Furthermore, under the public administration system, the role of the managers is limited to the following of the instructions and they have no effective role in improving the efficiency of their departments and their evaluation is not based on the following points: the output, results, total costs, relationship between the input and the output (efficiency) and the relationship between the output and the outcome (effectiveness)". 
para eleger os insumos que irão executar os serviços de maneira mais eficiente. No Reino Unido, por exemplo, diversos ministérios são livres para utilizar os recursos de cada programa da maneira como desejarem, sujeitos a duas restrições mínimas: primeiro, a quantidade de recursos atribuída aos gastos com pessoal não pode ser elevada e, segundo, as despesas de capital não podem ser movidas para as despesas comuns ${ }^{20}$. A França adota modelo similar em que se aplica apenas a primeira dessas restrições.

Assim sendo, considerando a extensão da matéria, os principais itens relevantes ao orçamento por resultados serão abordados em seguida: a flexibilidade administrativa - associada à responsabilidade institucional por resultados -, os mecanismos de incentivos e sanções no âmbito da Administração Pública para estimular o desempenho, e a gestão e avaliação de programas com ênfase em resultados.

\subsubsection{Flexibilidade gerencial e accountability por resultados}

A flexibilidade gerencial é outro elemento fundamental da Administração Pública por resultados, assim como do orçamento por resultados. De fato, a flexibilidade está umbilicalmente relacionada à responsabilidade institucional pelos resultados. Busca-se a mitigação da responsabilidade formal, voltada tão somente ao cumprimento das normas e protocolos, para privilegiar a responsabilidade material, centrada no resultado (outputs e outcomes) produzido pela gestão dos programas e pelo gasto das verbas públicas.

Sob o prisma da Administração Pública por resultados, os gestores devem gozar de maior flexibilidade gerencial e financeira na condução de suas atividades, e, de maneira correlata, estarão proporcionalmente submetidos à responsabilidade institucional (accountability) pelos resultados atingidos na gestão. Trata-se de permitir que os administradores administrem de fato - e não fiquem amarrados pelo excesso de procedimentos e controle formais.

Em troca dessa mudança de orientação da responsabilidade institucional (accountability), o gestor público deve passar a ter maior flexibilidade para atuar. Dá-se liberdade ao gestor; contudo, espera-se dele resultados.

As organizações e gestores devem, desse modo, possuir uma maior autonomia para a tomada de decisões. Essa reforma representa uma reorientação fundamental na responsabilização institucional dos administradores públicos, do modelo tradicional, em que os gestores orçamentários eram muito mais pressionados em razão dos insumos, sem haver, dessa maneira, uma obrigação sobre a qualidade

20 World Bank. Results, performance budgeting and trust in government. Washington D.C.: The International Bank for Reconstruction and Development/ The World Bank, 2010, p. 27. 
e quantidade dos produtos, para o modelo moderno, em que há uma maior discricionariedade sobre a alocação dos recursos a fim de atingir as metas de produtos preestabelecidas ${ }^{21}$.

Isso inclui um aumento da flexibilidade na alocação de insumos ${ }^{22}$, de sorte que os administradores possam distribuí-los da maneira mais efetiva para a prestação dos serviços. Pressupõe-se aí uma redução dos distintos limites por classificação econômica típicos do orçamento tradicional. Não obstante, é necessário que se mantenham limites para evitar casos de abuso e corrupção em áreas suscetíveis (como, por exemplo, publicidade, viagens, consultoria). De igual modo, é relevante a limitação de gastos com pessoal, como institui a Lei de Responsabilidade Fiscal (art. 19 e ss.), enquanto o regime de serviço de público permanece rígido.

A responsabilidade institucional pelos resultados advém, inclusive, da própria resposta da população em relação à gestão pública. Allen Schick esclarece que a razão para fornecer informações aos cidadãos a respeito do desempenho do governo, dentro do modelo de Administração Pública por resultados, é autoevidente - ainda mais nos termos do peso da responsabilização institucional nos Estados de direito. Há uma expectativa mais sólida de aprimoramento do desempenho do setor público quando as instituições realizadoras de gastos e os próprios gestores estatais são responsáveis pela maneira como desempenham suas funções.

Quanto à flexibilidade administrativa, Anwar Shah, do Banco Mundial, destaca dois modelos. O primeiro, "fazer com que os administradores administrem" (make the managers manage), é consubstanciado em contratos, e segue arranjos como os de mercado, fundados na competitividade e em incentivos na gestão pública; enquanto o segundo modelo consiste em "deixar que os administradores administrem" (let the managers manage), empoderando os administradores com

21 "Changes are directed at giving organizations and managers greater freedom at operational decisions and removing unnecessary constrains in resource management. In return organizations and managers are held more directly accountable for results. This represents a fundamental reorientation in accountability - from the traditional model where budget managers had their inputs constrained, with no constrains over quantity and quality of outputs, to a new situation where they are given discretion over the composition (although not the aggregate level), of inputs meet a contracted level of outputs, Australia, New Zealand, and most Nordic countries have led reforms in this direction, and initiatives in the United Kingdom and Canada reflect the same approach." DIAMOND, J. Performance budgeting: managing the reform process. Washington: Fundo Monetário Internacional - Departamento Fiscal, 2003, p. 4.

22 ROBINSON, M.; LAST, D. A basic model of performance-based budgeting. Fiscal affairs department. Technical Notes and Manuals 09/01. IMF, 2009, p. 8. 
arranjos de normas de administração e competência, que se fundam na boa fé e confiança ${ }^{23}$.

Os modelos diferem-se basicamente quanto ao modo de recompensar os servidores públicos. $\mathrm{Na}$ abordagem contratual (caso da Nova Zelândia), o diretor será recompensado financeiramente se a organização atingir metas de desempenho. $\mathrm{Na}$ abordagem de empoderamento (caso da Suécia e Austrália), os servidores são motivados pelas recompensas intrínsecas do método, como ter maior liberdade. No primeiro, busca-se a competitividade e incentivos para que os administradores sejam responsáveis, enquanto no segundo espera-se que os administradores sejam motivados ética e profissionalmente para desempenhar.

À evidência, em teoria, o primeiro modelo parece mais adequado em uma transição da cultura burocrática, sendo o segundo modelo um estágio mais avançado.

A responsabilidade institucional nesses sistemas é baseada em outputs - ou seja, nos produtos realizados pela gestão. A responsabilidade por resultados e impactos (outcomes) pode ser injusta, uma vez que inúmeros fatores residem fora do âmbito de controle dos gestores e servidores públicos.

Anwar Shah e Chunli Shen apontam três fatores principais para que a responsabilização seja feita por produtos: (i) é difícil e implausível conectar diretamente os resultados e impactos com ações e decisões do administrador, pois esses resultados interagem com vários fatores e podem se dar em diferentes ocasiões no tempo; (ii) resultados são imensamente difíceis de identificar e quantificar; e (iii) calcular o custo do esforço para atingir resultados é consideravelmente mais complexo do que identificar o custo dos produtos ${ }^{24}$.

Com a instituição da responsabilidade por produtos na administração, é fundamental que se dê a referida flexibilidade gerencial pela redução dos controles de insumos. Isso se dá do ponto de vista orçamentário na concentração de vários itens nas linhas do orçamento de custos operacionais em uma apropriação única de gasto, permitindo que o administrador escolha como o gasto será realizado, mas com responsabilidade pelos produtos.

Do ponto de vista administrativo (e até mais relevante nessa questão), a flexibilidade gerencial ocorre pela mitigação das regras que inibem a liberdade do administrador. As regras sobre administração de pessoal são especialmente relevantes

${ }^{23}$ SHAH, Anwar; SHEN, Chunli. A primer on performance budgeting. In: SHAH, Anwar (Coord.). Budgeting and budgetary institutions. The World Bank: 2007, p. 146-147.

${ }^{24}$ SHAH, A.; SHEN, C. A primer on performance budgeting. In: SHAH, Anwar (Coord.). Budgeting and budgetary institutions. The World Bank: 2007, p. 146-147. 
nesse ponto, tendo em vista que o gasto com pessoal é geralmente o maior componente dos gastos operacionais; assim, sem flexibilidade para administrar os colaboradores dos serviços públicos, dificilmente a consolidação dos itens no orçamento em direção a um objetivo terá algum impacto significativo na gestão ${ }^{25}$.

Com efeito, além da flexibilidade na alocação de insumos, um dos grandes elementos para o sucesso de um modelo de administração por resultados é também a flexibilidade dos processos da administração em si, inclusive quanto ao serviço público. Como bem destaca Robinson:

Se a priorização alocativa será aprimorada, é crucial que governantes tenham a capacidade de reduzir os empregos públicos em áreas de programas de baixa prioridade ou ineficazes. No entanto, em muitos países, governos não são capaz de sequer mover os servidores conforme a necessidade emerge. Maior flexibilidade do serviço público é, portanto, um importante elemento para o sucesso do orçamento por resultados e da administração por resultados ${ }^{26}$.

Eis aí uma das grandes dificuldades e desafios dos modelos de administração de resultados, especialmente no Brasil em que o regime jurídico do serviço público demandaria uma grande reestruturação para comportar tal novo caminho. A título de exemplo, no plano internacional: (i) a Nova Zelândia reestruturou todos os seus cargos estáveis, substituindo-os por posições contratuais, com base em resultados previstos nos contratos; (ii) a Suécia não possui serviço público como um todo no nível governamental, os diretores de agências são responsáveis por recrutar, promover e demitir os servidores públicos.

Tendo em vista os arranjos constitucionais de serviço público e o modelo consolidado no Brasil, com a cultura burocrática estabelecida, é forçoso reconhecer os grandes impasses à flexibilidade gerencial. No entanto, a crise de tal modelo, especialmente de sua previdência, é iminente e não há outro caminho a ser seguido, salvo a evolução desses mecanismos para a construção de um Estado sustentável no longo prazo e que entregue resultados à população.

25 SHAH, A.; SHEN, C. A primer on performance budgeting. In: SHAH, Anwar (Coord.). Budgeting and budgetary institutions. The World Bank: 2007, p. 146-147.

26 Tradução livre: "if expenditure priorization is to be improved, it is crucial that governments have the capacity to reduce civil service employment in low-priority or ineffective program areas. Yet, in many countries, governments are not able to even redeploy staff as needs arise. Greater civil service employment flexibility is, therefore, an important element to the success of performance-based budgeting and managing-for-results more generally". ROBINSON, M.; LAST, D. A basic model of performance-based budgeting. Fiscal Affairs Department. Technical Notes and Manuals 09/01. IMF, 2009, p. 8. 
Por sua vez, os mecanismos de incentivos e sanções podem ser desde logo contemplados para iniciar a direção em rumo a flexibilidade gerencial, como se verá adiante.

Por fim, conforme observa Allen Schick - e é preciso frisar bem esse ponto -, é necessário destacar que o orçamento por resultados não é capaz por si só de transformar as organizações públicas. O modelo pode ser uma reforma necessária para isso; entretanto, é essencial o movimento da Administração Pública no mesmo rumo ${ }^{27}$.

\subsubsection{Mecanismos de incentivos e sanções}

A administração por resultados também prevê o estabelecimento de incentivos e sanções para estimular o desempenho e fixar a responsabilidade institucional de gestores e servidores segundo os resultados atingidos. De início, indubitável que o principal mecanismo são os incentivos, que são essenciais para a introdução da reforma com o objetivo de avançar da cultura burocrática para uma cultura de efetiva produtividade.

Tendo em vista que um dos objetivos primários é evoluir o desempenho do governo, é preciso que o uso da informação de resultados seja feito para estimular o desempenho e, entre os mecanismos, compreendem-se incentivos como recursos, liberdade e reconhecimento das organizações, servidores e administradores ${ }^{28}$.

Em primeiro plano, os recursos estão relacionados à possibilidade de recompensas financeiras para agências, organizações, administradores e servidores de acordo com o desempenho, o que leva em conta os incentivos e sanções financeiras.

A liberdade, por seu turno, significa a possibilidade de flexibilizar os controles de insumos, no gasto, compras e contratações com pessoal. Além disso, há a opção por reconhecimento, de modo a tornar os resultados de desempenho público e comparar com outras organizações e servidores, de maneira a reconhecer publicamente o bom desempenho e evidenciar o desempenho ruim.

Nesse sentido, estabelecer arranjos de administração por resultados no contexto do orçamento por resultados significa atrelar os incentivos ao serviço público às prioridades políticas amplas do governo. O Banco Mundial afirma que as metas individuais operacionais de administradores e servidores podem explicitamente refletir metas mais amplas do serviço público:

27 Cf. SCHICK, A. The metamorphoses of performance budgeting. In: $34^{\text {th }}$ Annual Meeting of OECD Senior Budgeting Officials. OECD - GOV/PGC/SBO (2013), 27 de maio de 2013.

${ }_{28}$ CURRISTINE, T. Performance information in the budget process: results of the OECD 2005 questionnaire. OECD Journal on Budgeting, Paris: OECD, v. 5, n. 2, 2005, p. 107. 
Esse é o caso nos Estados Unidos, França e Reino Unido, onde o desempenho dos acordos de desempenho de agências tem efeito cascata diretamente nos acordos de desempenho dos administradores. No entanto, ao fazer isso, a experiência indica que é importante que haja uma clara linha de visão pelo labirinto dos objetivos e metas de desempenho do governo ${ }^{29}$.

Os incentivos são fundamentais para cooptar a cooperação do setor público com a mudança do ambiente institucional e trazer fatores positivos do modelo para os agentes envolvidos na atividade pública. A Constituição Federal já determina a indução à conduta positiva de servidores pela premiação, consoante a inteligência combinada dos arts. $39, \mathbb{S} 7^{\circ}$, e $37, \mathbb{S} 8^{\circ}$.

Segundo o art. 39, $\mathbb{S} 7^{\circ}$, as leis dos entes federativos poderão "estabelecer a relação entre a maior e a menor remuneração dos servidores públicos, obedecido, em qualquer caso, o disposto no art. 37, XI”. Por seu turno, o art. 37, $\mathbb{S} 8^{\circ}$, dispõe expressamente que a autonomia gerencial, orçamentária e financeira da administração direta e indireta poderá ser ampliada por contratos intra-administração, que tenham por objeto a fixação de metas de desempenho para o órgão ou entidade.

Não obstante, em que pese a expressa previsão constitucional que possibilita o estabelecimento de tais contratos no âmbito da Administração Pública, esse método não é amplamente utilizado como um paradigma para a gestão. As complexidades são muitas, desde os problemas intergovernamentais e partidários, à motivação e confiança dos servidores no governo para participar de tais modelos; todavia, decerto são bases constitucionais introduzidas com a "reforma da administração gerencial” que podem impulsionar mudanças.

O que se impõe, de fato, é uma mudança de cultura, para permitir a aplicabilidade adequada do dispositivo constitucional.

No mais, o regime diferenciado de contratações públicas (RDC) é ainda mais profundo no que tange ao desempenho nos contratos públicos, conforme os arts. $10,18, \mathrm{~V}$ e $23, \mathbb{S} 3^{\circ}$, da Lei n. $12.462 / 2011$, e é outro exemplo desse tipo de medida.

A contenção da conduta negativa no serviço público, por seu turno, se dá pelos mecanismos de sanção. Essas sanções, na maioria das vezes, derivam apenas do cumprimento de normas; no entanto, seria possível cogitar de uma responsabilidade em certo grau associada ao desempenho, exigido em uma plêiade de dispositivos constitucionais.

29 WORLD BANK. Results, performance budgeting and trust in government. Washington D.C.: The International Bank for Reconstruction and Development/The World Bank, 2010, p. 27. 
A administração cotidiana deveria pautar-se pela análise "bônus" e "ônus" no serviço público, para que exista verdadeira responsabilidade institucional pelo desempenho realizado. Entretanto, diversos bônus e benefícios (v.g. promoções), são concedidos sem base no mérito.

A cultura burocrática limita a avaliação do desempenho na medida em que, ao indivíduo que ultrapasse uma exigência mínima de desempenho, nada mais é aplicado - o que há é o poder disciplinar para aqueles que descumprem as exigências mínimas. E assim é que instrumentos jurídicos como o art. $37, \mathbb{S} 8^{\circ}$ e $39, \mathbb{S} 7^{\circ}$, da CRFB devem ser utilizados: especialmente esse último, que autoriza a instituição de prêmios por avaliações periódicas de resultados.

Há também problemas que devem ser considerados sobre sistemas de incentivos e sanções. Segundo Curristine ${ }^{30}$ :

Enquanto recompensar o bom desempenho é atrativo, isso não leva em consideração as limitações orçamentárias e as prioridades do governo. De fato, alguns Ministérios de Finanças argumentam que os ministérios com gastos tendem a ver planos de desempenho, metas e resultados como veículos para obter mais financiamento ao invés de métodos para aprimorar o desempenho. Em um clima de economia orçamentária, a questão é se deve-se dar recursos adicionais a uma agência, especialmente uma que não seja prioridade do governo. Em ambos casos, sempre há o risco de conectando resultados com recursos financeiros criar-se incentivos para distorcer e trapacear a apresentação da informação de desempenho.

\subsubsection{Gestão e avaliação de programas por desempenho}

A administração por resultados pressupõe ainda que os programas do governo sejam administrados e avaliados segundo o desempenho. Consoante, e de acordo com a observação de Allen Schick, o aumento da transparência e o monitoramento do desempenho estatal em um conceito de Administração Pública por resultados implica uma análise da idoneidade dos programas e dos gastos estatais em relação aos seus objetivos ${ }^{31}$.

${ }^{30}$ CURRISTINE, T. Performance information in the budget process: results of the OECD 2005 questionnaire. OECD Journal on Budgeting, Paris: OECD, v. 5, n. 2, 2005, p. 108.

31 "Performance monitoring is a means of making governments more transparent and accountable for the money they spend and the results they deliver. On the expenditure side monitoring abets determination of whether funds have been spent on intended purposes, for example, whether money allocated for textbooks has actually been received by eligible schools. In terms of performance, vigilant monitoring sheds light on the quality and volume of services and whether policies have produced targeted results". SCHICK, A. The metamorphoses of performance budgeting. In: 34th Annual Meeting of OECD Senior Budget Officials. Paris: OECD, 2013, p. 27. 
Tendo em vista o aspecto do desempenho do setor público, esse modelo de gestão estatal permite uma análise e uma clareza maiores sobre a qualidade e quantidade dos serviços públicos fornecidos a população, bem como uma avaliação dos resultados e impactos produzidos pelas diversas políticas públicas em relação ao que foi pretendido em sua fase de planejamento.

Jack Diamond traça os principais aspectos para a gestão e avaliação de programas conforme o desempenho, orientando-se na perspectiva do orçamento programa. O ponto de partida é a análise dessas atividades governamentais em conexão com os objetivos dos governos subjacentes às respectivas atividades trata-se de conectar operações de cada organização pública que realiza gastos com a implementação das políticas do seu setor ${ }^{32}$.

As funções amplas dos setores podem ser divididas em subfunções, e estas, em programas que são construídos a partir de um número de atividades. Em seguida, essas atividades e projetos são consideradas como centro de custos para os quais o gasto pode ser direcionado.

Nesse sistema, a ideia é que a estrutura de programas faça a conexão entre o orçamento e o planejamento estratégico, refletindo a arquitetura institucional das políticas públicas e das operações governamentais. Programas passam a ser muito mais do que uma maneira de classificar o gasto, mas uma ferramenta de análise política - ou melhor, de avaliação dos programas por desempenho. Nos programas, pode-se considerar o que deve ser financiado, quais níveis de fundos devem ser aplicados e o impacto político decorrente dessa aplicação de fundos.

A análise dos programas e a gestão da implementação dos programas, por conseguinte, deve ser pautada nos princípios do orçamento por resultados e na concepção de desempenho. Isso abrange não só o ponto de vista orçamentário, mas também o modo de condução das atividades na Administração Pública.

\subsection{FUNDAMENTOS DA INFORMAÇÃO DE RESULTADOS}

\subsubsection{O orçamento moderno e a informação de desempenho}

A informação de resultados traduz-se em elemento essencial do orçamento por resultados, tendo em vista que o modelo, em um primeiro momento, ocupa-se da produção dos dados de desempenho, sua incorporação no processo orçamentário e consequente utilização nos processos de tomada de decisão pelos gestores

32 Os trechos em seguida são baseados no conceito de gestão e avaliação exibidos em: DIAMOND, J. From program to performance budgeting: the challenge for emerging market economies. Washington: Fundo Monetário Internacional - Departamento Fiscal, 2003, p. 12. 
financeiros. Apesar de a matéria orbitar principalmente no campo econômico dos indicadores, parece relevante também sua compreensão no âmbito jurídico para perceber os desafios em torno da apuração do desempenho das políticas públicas.

O estudo do tópico é indispensável para compreender os desafios, benefícios, tendências e problemas estruturais que acompanham o ambicioso empreendimento de produzir dados sobre o desempenho do poder público e integrá-los no processo orçamentário, de maneira a impulsionar a eficiência e a efetividade da alocação dos recursos públicos nas tomadas de decisão.

Como bem narram Stiglitz, Sen e Fitoussi, o argumento de que é necessário monitorar e avaliar o desempenho - de países, empresas ou indivíduos - é um lugar comum ultimamente. A sociedade espera resultados de seus gestores, trabalhadores ou políticos, de sorte que as recompensas individuais devem ser dadas tipicamente com base no desempenho, enquanto quaisquer sistemas de incentivos devem ser instituídos com base em medidas, de modo que:

O que nós medimos afeta, obviamente, o que nós fazemos. E o que individualmente ou coletivamente nós estamos pretendendo, afeta o que nós medimos. Há uma relação intrínseca entre objetivos, medidas e ações. Se professores são recompensados pelo desempenho de alunos em provas de leitura, eles irão ensinar leitura, talvez ao custo de habilidades cognitivas mais amplas ${ }^{33}$.

Logo, nota-se que o monitoramento e a avaliação de resultados não criam impactos tão somente sobre o processo de gestão pública e sobre o processo orçamentário, mas também possuem uma característica indutora de comportamentos, de tal forma que as medidas eleitas (metas, objetivos, indicadores, produtos e resultados) irradiam efeitos sobre a condução direta das atividades por parte dos diversos agentes mais amplamente envolvidos no exercício da atividade governamental e na condução das políticas públicas; ou, de modo mais amplo, incidindo sobre os todos os indivíduos relacionados direta ou indiretamente à medida de desempenho eleita. Ao eleger uma medida, privilegia-se um determinado objetivo, induzem-se certos comportamentos, seja de maneira planejada, seja ocasional.

33 Tradução Livre: "What we measure affects, of course, what we do. And what individually or collectively we are aiming at affects what we measure. There is an intricate relationship between objectives, measures and actions. If teachers are rewarded for their students' performance on reading test scores, they will teach reading, perhaps at the expense of broader cognitive skills". STIGLITZ, Joseph; SEN, Amartya; FITOUSSI, Jean-Paul. The measurement of economic performance and social progress revisited: reflections and overview. Paris: Commission on the Measurement of Economic Performance and Social Progress, 2009, p. 8. 
Daí pode-se extrair uma dimensão material da informação de resultados, para além da sua simples acepção meramente técnica como insumo dos processos que demandam a utilização dos dados de desempenho.

Apesar de ser indutora de comportamentos devido aos seus aspectos intrínsecos, é a informação de resultados que deve instruir, sob a lógica do orçamento por resultados, entre outros relevantes fatores, os processos de planejamento-financeiro. Dessa forma, é preciso que sejam construídas metas, objetivos e indicadores com clareza, validade, confiabilidade e oportunidade durante o processo orçamentário, entre os outros requisitos inerentes às informações de resultados.

Grizzle ressalta que há duas condições cruciais para que as reformas orçamentárias, como o performance-based budgeting, PPBS ou orçamento base-zero, tenham sucesso. A primeira consiste em uma reformulação dos formatos de informação que permitam aos gestores financeiros analisar os pedidos de verba com base no desempenho. A segunda diz respeito à utilização dessas informações pelos formuladores de políticas públicas.

A despeito disso, não se pode ignorar que o processo orçamentário é eminentemente político, de sorte que todos envolvidos no processo devem ter participação ativa na aceitação dos indicadores como aptos a avaliar o desempenho (pode-se dizer, assim, que além do elemento técnico das informações de resultados, é preciso considerar o ambiente político institucional sobre o qual as técnicas são aplicadas $)^{34}$.

O Brasil tem buscado desenvolver com cada vez maior tecnicidade os indicadores de políticas públicas, à vista da evolução do planejamento plurianual e de um foco intensificado nas políticas sociais desde a Constituição de $1988^{35}$. Ainda assim, os sistemas de informação são relativamente novos e demandam maior desenvolvimento quanto à produção de dados - especialmente no tocante à utilização destes dados no processo orçamentário.

34 A respeito: "If budget reforms are to lead to improved budget outcomes, the presence of two conditions is critical. First, information changes that permit budgeters to analyze requests in terms of the performance criteria that the reform proponents advocate must accompany format changes. Second, policy makers must take this information into account when making budget decisions”. GRIZZLE, Gloria A. Performance measures for budget justifications. In: MILLER, Gerald J.; HILDRETH, W. Bartley; RABIN, Jack (Coord.). Performance-based budgeting. The American Society for Public Administration, Boulder, Colorado, USA: 2001, p. 365.

35 JANNUZZI, Paulo de Martino. Indicadores para diagnóstico, monitoramento e avaliação de programas sociais no Brasil. Revista do Serviço Público, Brasília, 56(2):137-160, abr./jun. 2005, p. 137-138. 
Nesse sentido, os seguintes itens abordarão: (i) a importância da informação de resultados para o processo orçamentário, de modo a identificar sua relevância e pertinência aos propósitos do modelo; (ii) o desafio da mensuração da performance, trazendo à baila algumas das grandes dificuldades inerentes à criação de sistemas de informação dirigidos a aferir o desempenho de atividades públicas; (iii) os requisitos de viabilidade da informação de resultados, a fim de traçar os elementos técnicos constitutivos dos indicadores de desempenho; (iv) as modalidades da informação de desempenho, subdivida para fins didáticos entre os indicadores de performance e avaliações; (v) a classificação de programas, metas, objetivos, produtos e resultados, com objetivo de estabelecer conceitos e definições sobre cada um destes elementos da informação de resultados; e (vi) a transparência dos sistemas de informação, que abarca uma das mais relevantes discussões da agenda atual: a transparência da gestão pública.

\subsubsection{A importância e funções da informação de resultados}

Sob este prisma, mostra-se nítida a importância da informação de resultados no modelo de orçamento por resultados. A informação sistemática sobre a eficiência e efetividade da atividade governamental, financiada por meio de recursos públicos, é um dos componentes fulcrais do orçamento por resultados e também da Administração Pública por resultados, permitindo aos gestores a tomada de decisões mais precisas ${ }^{36}$.

Cabe alertar que, a despeito da relevância da informação de resultados que, de fato, assume papel de protagonismo no modelo -, a utilização desta informação é de igual importância, de modo que a simples existência da informação, sem qualquer utilidade, determinará o fracasso do sistema ${ }^{37}$.

36 "Systematic information about the efficiency and effectiveness of public expenditure is the most fundamental tool of performance-based budgeting, and of managing-for-results more generally. Only if reliable and timely information is available about the results being delivered by government actions will it be possible to make performance-informed budget decisions." ROBINSON, M.; LAST, D. A basic model of performance-based budgeting. Washington: Fundo Monetário Internacional - Departamento Fiscal, 2009, p. 3.

37 Sobre este tema, Faria retrata com precisão: "a informação sobre desempenho (performance information) representa o coração do modelo de orçamento por resultados. Sem que tal informação esteja disponível não há possibilidade de implementação do modelo; contudo, a mera disponibilidade não garante que seja utilizada no processo de tomada de decisão. Em outras palavras: a informação sobre desempenho é condição necessária, mas não suficiente”. FARIA, Rodrigo Oliveira de. Orçamento por resultados: tendências, perspectivas e desafios. Novas abordagens do orçamento público. III Prêmio SOF de Monografias. SOF: 2009, p. 16. 
Terá como objetivo primordial subsidiar a análise do gasto realizada pelo gestor financeiro e pelos diversos agentes envolvidos nos processos de tomada de decisão no orçamento público (a informação sobre resultados aprimora o processo de decisão no aspecto qualitativo); como objetivos secundários, a indução de comportamentos em todos os níveis da atividade governamental, dirigindo-os a partir das metas fixadas e indicadores escolhidos, e o fornecimento de informações claras e nítidas para a população a respeito do desempenho do poder público, impulsionando a transparência e o controle democrático.

Por meio da informação de resultados, os rumos dos programas de governo, das atividades das agências, e da prestação de serviços públicos podem ser ajustados para seguir os objetivos fixados. Para além da ótica orçamentária, os dados de desempenho auxiliam na condução das políticas públicas, trazendo à baila problemas, oportunidades, custo-benefício, e permitem que os arranjos institucionais e o conceito dos programas estabelecidos no orçamento, bem como dos programas de ação governamental, sejam reformulados em harmonia com as efetivas necessidades sociais ${ }^{38}$.

Curristine indica que os principais objetivos entre os países da OCDE para instituição de sistemas de informação de resultados estão relacionados, em primeiro plano: (i) ao aprimoramento da eficiência e efetividade das organizações e programas governamentais; (ii) ao fornecimento de informações mais concretas ao governo e ao Poder Legislativo sobre o desempenho para o propósito de tomada de decisões e para o estabelecimento de futuras metas e prioridades. Em segundo plano, os principais objetivos são: (i) auxiliar na redução do gasto público; (ii) fornecer informações para auxiliar na realocação de recursos entre atividades/ programas; e (iii) fornecer um mecanismo para o Ministério da Fazenda monitorar as atividades de organizações/agências e o seu desempenho ${ }^{39}$.

Assim, no primeiro plano, o aprimoramento da eficiência e efetividade das organizações e programas governamentais decorre da devida utilização da informação de desempenho produzida, de maneira a orientar escolhas públicas que impliquem uma melhor alocação dos recursos públicos, de acordo com os dados aferidos.

Além disso, o diagnóstico, monitoramento e avaliação das organizações e programas, tendo por base a informação de resultados, torna possível o ajuste dos

38 Cf. FARIA, Rodrigo Oliveira de. Orçamento por resultados: tendências, perspectivas e desafios. Novas abordagens do orçamento público. III Prêmio SOF de Monografias. SOF: 2009, p. 13.

39 CURRISTINE, Teresa. Performance information in the budget process: results of the OECD 2005 questionnaire. OECD Journal on Budgeting, v. 5, n. 2, 2005, p. 96. 
rumos sendo tomados e a reformulação de arranjos e desenhos, buscando a máxima efetividade. Tem-se aqui materializado um dos principais objetivos do orçamento de desempenho.

O sistema de informação de resultados impacta também diretamente a execução dos programas e as atividades desenvolvidas pelas organizações, na medida em que o constante monitoramento destas atividades e sua influência nas escolhas que serão tomadas, afeta o ambiente institucional, estimulando o atingimento das metas fixadas.

O segundo ponto indicado por Curristine relaciona-se umbilicalmente com o primeiro. Diz respeito ao fornecimento de informações mais concretas ao governo e ao Poder Legislativo sobre o desempenho para o propósito de tomada de decisões no âmbito administrativo e orçamentário, e para a fixação de metas e prioridades futuras. Com a disponibilização das informações, as autoridades governamentais participantes do processo orçamentário estão aptas a tomar a decisões efetivamente informadas, a partir de dados concretos que refletem a realidade dos programas, em contraste com os resultados esperados pela sociedade.

Isso não significa que as escolhas sejam predeterminadas a partir da informação de resultados; na verdade, estas servem de subsídio para que as decisões tomadas no aspecto político quanto aos resultados esperados (planejamento social) possam estar adequadamente refletidas nos meios que concretizarão tais resultados, ou seja nos programas e atividades atrelados às metas e prioridades. Trata-se de uma bússola que auxilia o comandante na direção e no sentido, a fim de que este alcance o seu destino.

É de igual maneira que a própria escolha das metas e prioridades também é auxiliada. $\mathrm{Na}$ medida em que se conhece com precisão a realidade concreta, a tendência e o desempenho de cada uma das atividades e programas, tem-se subsídio mais sólido para identificar as metas necessárias no presente e as prioridades essenciais que devem ser desenvolvidas para perseguir os objetivos de Estado.

Abaixo desses dois principais aspectos, a informação de resultados carrega também três objetivos de segundo plano que merecem destaque.

O primeiro é a redução do gasto público, pois, com a possibilidade de análise dos serviços públicos, programas, atividades e organização a partir de resultados diagnosticados, a avaliação de custo-benefício ou economicidade na alocação de recursos torna-se mais simples, clara, objetiva e meritocrática. Ressalve-se que tal análise não deve ser automática, sob pena de se desprezar os elementos políticos. Eventuais cortes na agenda governamental e no gasto podem, dessa forma, ser estabelecidos à luz de critérios concretos, a fim de otimizar o desempenho das políticas. 
De modo análogo, o segundo objetivo secundário é a realocação de recursos entre atividades e programas. De posse da informação de resultados, o remanejamento de recursos públicos é facilitado por meio de critérios técnicos. A verba pode ser distribuída em consonância com a necessidade alocativa. Programas efetivos podem ser ampliados, enquanto programas sem efetividade podem ser reduzidos ou suprimidos. Ineficiências podem ser identificadas e sanadas. Recursos alocados em excesso para determinadas finalidades poderão ser redistribuídos para outras que mais dele necessitem.

Enfim, um terceiro aspecto secundário está associado ao monitoramento pela autoridade central orçamentária das atividades de organizações e agências e o seu desempenho. Trata-se de um mecanismo que busca, na máxima medida possível, permitir o monitoramento por meio de critérios técnicos adequadamente selecionados e que estejam relacionados a resultados. Espera-se com isso que autoridades hierarquicamente superiores do ponto de vista da administração financeira possam ter uma visão mais realista do que se passa no plexo de órgãos inferiores quanto ao desempenho do dispêndio das verbas públicas.

Por fim, consoante à lição de Shah e Chen, cabe salientar que um sistema de orçamento de resultados demanda um conjunto de medidas para avaliar os programas públicos por meio de uma variedade de filtros, tais como insumos, produtos (outputs - referindo-se a quantidade e qualidade de bens e serviços produzidos), eficiência (refere-se ao custo por unidade para produção dos produtos), qualidade dos serviços (medidas como disponibilidade, acessibilidade, cortesia, precisão e satisfação) e resultados (entendidos como o progresso em atingir objetivos fixados nos programas). $\mathrm{O}$ uso desse conjunto completo de indicadores difere de um indicador único derivado de uma relação incerta entre insumos, processos e resultados, tradicional nos programas públicos.

Em síntese, a qualidade dos serviços ou os resultados dos programas públicos não podem ser identificados simplesmente por seus produtos (outputs); é preciso que se avalie toda a cadeia de resultados a fim de se compreender e administrar os programas governamentais ${ }^{40}$.

\subsubsection{O desafio da mensuração de performance}

A demanda pela melhora da qualidade do gasto público é crescente, afetando a sociedade brasileira fortemente em virtude do baixo retorno da carga tributária em benefícios para a população e de uma elevada taxa de desperdício dos

40 SHAH, Anwar; SHEN, Chunli. A primer on performance budgeting. In: SHAH, Anwar (Coord.). Budgeting and budgetary institutions. Washington: The World Bank, 2007, p. 145-146. 
recursos públicos. O desempenho do poder público tornou-se uma das grandes preocupações da sociedade civil, que vem exigindo maior responsabilização e transparência da gestão. Esse tema, no entanto, é desafiado por sua própria natureza. Nesse sentido:

A sociedade em geral tem apresentado uma crescente preocupação com a responsabilização e transparência do governo, o que resulta em uma demanda por qualidade no gasto público. Essa melhoria da qualidade pressupõe melhorar a eficiência e a eficácia da despesa, para garantir que a oferta de bens e serviços seja feita com menor custo possível e gere o máximo de benefícios para a sociedade.

Apesar disso a literatura recente é escassa em estudos sistemáticos sobre desempenho do setor público no provimento de bens e serviços à sociedade. Algumas razões para essa situação são a ausência de padronização no uso de indicadores, a falta de produção sistemática de estatísticas confiáveis atualizadas, a dificuldade de definição do resultado dos serviços prestados e o debate político centrado nos montantes financeiros como a melhor forma de melhorar a situação de um determinado setor ${ }^{41}$.

Em que pese a aparente lógica e simplicidade da ideia de avaliar os resultados dos programas governamentais em contraste com o gasto realizado, de modo a informar o planejamento financeiro estatal nas decisões orçamentárias futuras e efetuar o controle das despesas com base no seu aspecto material, a sua realização no plano concreto é árdua ${ }^{42}$.

Avaliar o desempenho da atividade governamental é um desafio crescente, pois a medição da efetivação dos direitos estabelecidos no ordenamento jurídicos revela uma atividade intrinsicamente complexa, levando-se em conta a vasta gama de fatores e parâmetros subjetivos que se colocam sob apreciação.

${ }^{41}$ VELOSO, João Francisco Alves. Os determinantes do desempenho do gasto público: uma breve revisão da literatura recente. In: REZENDE, Fernando; CUNHA, Armando (Org.). A reforma esquecida: orçamento, gestão pública e desenvolvimento. Rio de Janeiro: Editora FGV, 2013, p. 327.

42 Sobre este ponto, Élida Graziane Pinto leciona, com maestria: "Se soubéssemos coletivamente avaliar programas, mensurando seus resultados em face dos seus custos e contrastando o planejado em face do realizado, teríamos maior transparência, eficiência e efetividade no trato dos recursos públicos. O caráter trágico de tal constatação reside no fato de que, a despeito de parecer simples no campo do discurso abstrato, complexo é operacionaliza-la no mundo da vida em sociedade”. PINTO, Élida Graziane. Controle das políticas governamentais e qualidade dos gastos públicos: a centralidade do ciclo orçamentário. Revista TCEMG, jan./mar. 2015, p. 8 . 
De forma diversa da atividade empresarial que busca o lucro como sua principal finalidade, o Estado enfrenta um amálgama de objetivos diversos que podem ser de difícil mensuração. Apurar adequadamente os indicadores corretos para serviços como saúde, educação, saneamento básico, serviços sociais é uma tarefa dura, cujo aspecto técnico-científico está sempre em evolução.

Com efeito, ao empreender a mensuração dos resultados de políticas públicas e atividades governamentais, é preciso muitas vezes superar o problema de como medir resultados intangíveis. Sobre essa problemática, Rattner evidencia a importância da seleção adequada dos indicadores, considerando que o grau de cientificidade que a eles se atribui imprime um caráter tecnocrático, de maneira que "à falta de hipóteses teoricamente fundamentadas, corre-se o perigo de obter resultados mais exatos do que significativos”. É neste raciocínio que o autor anota:

O tratamento matemático e estatístico das informações colhidas mediante censos e levantamentos, utilizando como esquema básico de inferência, correlações e a análise multivariacional, confere a estas técnicas o prestígio e a fidedignidade que normalmente são atribuídos aos resultados da experimentação, nas ciências naturais ${ }^{43}$.

Desse modo, é preciso ter profunda cautela na seleção dos indicadores sociais e das informações de resultados a serem consideradas como um todo. É preciso obter resultados significativos - e não simplesmente exatos - porque é factível que no mundo do papel, dos números, dos indicadores, expressem-se informações que não beneficiam de fato a implementação de determinado programa ou objetivo do Estado ou mesmo a evolução de algum aspecto social que se procure avançar.

Um exemplo bastante controverso, nesse sentido, é a atuação do Poder Judiciário: como medir adequadamente a prestação jurisdicional? Quais conflitos emergem de uma avaliação qualitativa em contraste com uma avaliação quantitativa? É mais importante o Poder Judiciário resolver casos em consonância com o ordenamento jurídico ou entregar uma resposta rápida? Como conciliar eventuais controvérsias inerentes ao desempenho de tal atividade?

O Conselho Nacional de Justiça vem buscando responder essas e outras questões quanto à atividade jurisdicional; todavia, é certo que a matéria ainda é pano de fundo de inúmeras controvérsias, como, por exemplo, até que ponto a quantidade de sentenças elaboradas por um magistrado mede a sua eficiência -

43 RATTNER, Henrique. Planejamento e bem-estar social. São Paulo: Perspectiva, 1979, p. 151-164. 
esse fator não pode ser levado em conta isoladamente: há um conjunto de informações que se deve ter em consideração, como, entre outros, a complexidade dos casos que lhe são submetidos, a diversidade de matérias e a estrutura que lhe é oferecida pelo Poder Judiciário. Nesse sentido, vale reproduzir abaixo um quadro exemplificativo dos indicadores de litigiosidade, a fim de ilustrar a questão:

Tabela 1 Indicadores de litigiosidade por ramo de justiça e por instância. CNJ em números, 2013.

\begin{tabular}{|c|c|c|c|c|c|}
\hline \multicolumn{6}{|c|}{$2^{\circ} \mathrm{GRAU}$} \\
\hline Ramo de Justiça & $\begin{array}{l}\text { Taxa de } \\
\text { Congestionamento }\end{array}$ & $\begin{array}{l}\text { Baixados por } \\
\text { Caso Novo }\end{array}$ & $\begin{array}{l}\text { Sentenças por } \\
\text { Magistrado }\end{array}$ & $\begin{array}{l}\text { Baixados por } \\
\text { Magistrado }\end{array}$ & $\begin{array}{l}\text { Baixados por Servidor } \\
\text { da área judiciária }\end{array}$ \\
\hline Justiça Estadual & $45,2 \%$ & $96,6 \%$ & 1.292 & 1.193 & 108 \\
\hline Justiça Federal & $61,7 \%$ & $115,9 \%$ & 4.565 & 4.524 & 158 \\
\hline $\begin{array}{l}\text { Justiça do } \\
\text { Trabalho }\end{array}$ & $26,6 \%$ & $97,4 \%$ & 1.363 & 1.232 & 74 \\
\hline Justiça Eleitoral & $20,7 \%$ & $106,7 \%$ & 290 & 270 & 43 \\
\hline $\begin{array}{l}\text { Justiça Militar } \\
\text { Estadual }\end{array}$ & $27,8 \%$ & $119,1 \%$ & 150 & 137 & 46 \\
\hline $\begin{array}{l}\text { Total do Poder } \\
\text { Judiciário }\end{array}$ & $46,3 \%$ & $99,9 \%$ & 1.507 & 1.403 & 102 \\
\hline \multicolumn{6}{|c|}{$1^{\circ} \mathrm{GRAU}$ E JUIZADOS ESPECIAIS } \\
\hline Ramo de Justiça & $\begin{array}{l}\text { Taxa de } \\
\text { Congestionamento }\end{array}$ & $\begin{array}{l}\text { Baixados por } \\
\text { Caso Novo }\end{array}$ & $\begin{array}{l}\text { Sentenças por } \\
\text { Magistrado }\end{array}$ & $\begin{array}{l}\text { Baixados por } \\
\text { Magistrado }\end{array}$ & $\begin{array}{l}\text { Baixados por Servidor } \\
\text { da área judiciária }\end{array}$ \\
\hline Justiça Estadual & $75,2 \%$ & $96,3 \%$ & 1.415 & 1.648 & 132 \\
\hline Justiça Federal & $65,3 \%$ & $135,6 \%$ & 1.345 & 1.998 & 222 \\
\hline $\begin{array}{l}\text { Justiça do } \\
\text { Trabalho }\end{array}$ & $49,6 \%$ & $98,2 \%$ & 1.113 & 1.152 & 144 \\
\hline Justiça Eleitoral & $59,4 \%$ & $46,5 \%$ & 120 & 107 & 27 \\
\hline $\begin{array}{l}\text { Justiça Militar } \\
\text { Estadual }\end{array}$ & $47,8 \%$ & $112,2 \%$ & 222 & 253 & 30 \\
\hline $\begin{array}{l}\text { Total do Poder } \\
\text { Judiciário }\end{array}$ & $72,1 \%$ & $98,7 \%$ & 1.370 & 1.606 & 133 \\
\hline
\end{tabular}




\begin{tabular}{|l|c|c|c|c|c|}
\hline \multicolumn{5}{|c|}{ TOTAL DO PODER JUDICIÁRIO } \\
\hline Ramo de Justiça & $\begin{array}{l}\text { Taxa de } \\
\text { Congestionamento }\end{array}$ & $\begin{array}{l}\text { Baixados por } \\
\text { Caso Novo }\end{array}$ & $\begin{array}{l}\text { Sentenças por } \\
\text { Magistrado }\end{array}$ & $\begin{array}{l}\text { Baixados por } \\
\text { Magistrado }\end{array}$ & $\begin{array}{l}\text { Baixados por Servidor } \\
\text { da área judiciária }\end{array}$ \\
\hline Justiça Estadual & $73,3 \%$ & $96,2 \%$ & 1.423 & 1.611 & 132 \\
\hline Justiça Federal & $65,3 \%$ & $125,0 \%$ & 1.751 & 2.272 & 223 \\
\hline $\begin{array}{l}\text { Justiça do } \\
\text { Trabalho }\end{array}$ & $46,8 \%$ & $98,0 \%$ & 1.153 & 1.164 & 124 \\
\hline Justiça Eleitoral & $53,6 \%$ & $51,7 \%$ & 134 & 120 & 29 \\
\hline $\begin{array}{l}\text { Justiça Militar } \\
\text { Estadual }\end{array}$ & $41,9 \%$ & $114,6 \%$ & 185 & 193 & 34 \\
\hline $\begin{array}{l}\text { Tribunais } \\
\text { Superiores }\end{array}$ & $52,6 \%$ & $102,3 \%$ & 6.817 & 5.719 & 160 \\
\hline Auditoria Militar & $53,4 \%$ & $99,0 \%$ & 57 & 53 & 132 \\
\hline $\begin{array}{l}\text { Total do Poder } \\
\text { Judiciário }\end{array}$ & $\mathbf{6 9 , 9 \%}$ & $\mathbf{9 8 , 5 \%}$ & $\mathbf{1 . 4 5 0}$ & $\mathbf{1 . 6 2 8}$ & 17 \\
\hline
\end{tabular}

Além disso, o desenvolvimento da capacidade de inclusão de informação de resultados significativa é um trabalho de elevada complexidade que requer tempo, investimento e tecnologia para a sua adequada instituição.

Os sistemas, aliás, são distintos, peculiares e customizados de acordo com as pretensões governamentais a respeito dos objetivos a serem alcançados. Podem, por exemplo, estar ligados de forma mais próxima às decisões orçamentárias e à eficiência administrativa em geral (caso do Chile) ou podem ser voltados ao monitoramento de programas de governo e à promoção da responsabilidade institucional por resultados (como no caso da Finlândia). Certo é que todo sistema irá observar peculiaridades e enveredar com maior destaque por algum sentido político-institucional, uma vez que é inviável imaginar um sistema que possa amalgamar diretamente todos os fatores necessários e de interesse público, até por força dos limites da informação ${ }^{44}$.

44 “Countries' experiences show that it takes time and practice to develop meaningful performance information. The type of information and systems developed should depend on how the reformers intend to use such information. Is it to be closely linked to budget decisions and overall administrative efficiency like in Chile? Or is it to be used for monitoring government programmes and promoting public accountability for results like in Finland?” ORGANISATION FOR 
Os desafios são inúmeros. A despeito disso, Robinson relata que o maior desafio no desenvolvimento de um modelo-básico de orçamento por resultados é manter a informação de resultados simples, utilizável e acessível ${ }^{45}$.

Segundo o autor, aqueles que pretendem adotar a esse modelo orçamentário desenvolvem sistemas desnecessariamente complexos que necessitam de um corpo de funcionários extremamente qualificados e que acabam sendo demasiadamente caros. É muito mais sugestível que os países desenvolvam, inicialmente, um sistema mais simples de análise, com indicadores-chave para cada ministério ou agência e, consequentemente, para cada programa, ao invés de alocar ostensivas quantidades de recursos em uma metodologia mais complexa de estudo de desempenho.

A transparência é outro desafio a ser enfrentado. A constituição dos sistemas de informação e seu ambiente devem ser transparentes e imunes a qualquer tipo de manipulação por parte das organizações e atores participantes do seu manuseio. Daí é que importante a execução de auditorias nas informações, seja por entidades estatais especificamente designadas, seja por organizações externas especializadas nesse tipo de avaliação.

No plano internacional, a OCDE promoveu questionário abrangente efetuado em relação a diversos países que adotam algum sistema de informação por resultados e apontou os seguintes desafios principais, em ordem de importância: em primeiro plano, (i) dificuldades em atribuir resultados (outcomes) a programas específicos; (ii) dificuldades em projetar um indicador para uma atividade específica; (iii) insuficiente suporte político para esse tipo de trabalho; em segundo plano: (i) falta de clareza dos objetivos fixados; (ii) dados insuficientes ou de baixa qualidade ${ }^{46}$.

ECONOMIC CO-OPERATION AND DEVELOPMENT. Sequencing and pacing of performance budgeting reforms: summary of the 5th Annual Meeting of the SBO Network on Performance and Results. OCDE, Paris, 2008, p. 5.

45 "The biggest challenge in the development of a basic model of performance-based budgeting is keeping this performance information simple, affordable, and usable. All too often, newcomers to performance-based budgeting, including LICs, have set out to develop sophisticated performance information systems over short time periods (as little as a year or two). They fail to fully realize that such information is expensive and requires skilled human resources which may not be readily available or affordable. It is worth remembering here that similar systems in OECD countries took decades to develop." ROBINSON, M.; LAST, D. A basic model of performance-based budgeting. Washington: Fundo Monetário Internacional - Departamento Fiscal, 2009, p. 4.

${ }^{46}$ CURRISTINE, Teresa. Performance information in the budget process: results of the OECD 2005 questionnaire. OECD Journal on Budgeting, v. 5, n. 2, 2005, p. 100. 
No primeiro ponto, é preciso levar em conta a distinção entre produtos (outputs) e resultados (outcomes), conforme se demonstrará com mais detalhes na descrição das modalidades da informação de resultados.

Nesse caso, o desafio que se apresenta é encontrar quais são os resultados efetivos, apurados a partir dos impactos causados na realidade pela implementação do programa - e, em certos casos, essa tarefa pode ser árdua. Em geral, é mais simples aferir o produto (output) advindo dos recursos aportados do que encontrar os indicadores adequados para apontar os resultados. O segundo ponto está relacionado à questão da projeção de indicadores, com sua complexidade inerente. As maiores dificuldades estão nos setores de saúde e educação.

O terceiro desafio identificado pela OCDE - e essencial - é a questão do suporte político para os sistemas de informação. Como já se expôs, o sucesso do orçamento por resultados e da instituição de sistemas de informação dependem de um ambiente institucional adequado para acolher as mudanças instituídas. É necessário que se tenha envolvimento direto dos setores da Administração Pública e dos partícipes do processo de composição da informação de resultados. E isso apenas se dá com o suporte político adequado.

Os administradores políticos, membros do Poder Legislativo e autoridades envolvidas no processo de elaboração do orçamento devem estar comprometidos com a formulação de um sistema efetivo de informação por resultados; contudo, para muitos, não há um interesse real do ponto de vista político em se ter um seguimento perene e comprometido com esse tipo de procedimento. Os mecanismos que perpetuam as características burocráticas do sistema orçamentário aqui ecoam em resistência à cultura do desempenho.

Os desafios secundários destacados pela OCDE, por sua vez, parecem de extrema importância para os países em desenvolvimento. A falta de objetivos claros na introdução da informação de resultados impede que o sistema evolua e que os utilitários compreendam e tomem parte do processo de desenvolvimento e avaliação dessas informações, prejudicando o contexto em que são inseridas.

A existência de dados insuficientes e de baixa qualidade, por seu turno, resultarão em uma informação que dificilmente será útil para balizar os processos decisórios. Assim sendo, a clareza nos objetivos e a coleta de dados suficientes com qualidade - são fatores que devem sempre ser endereçados, sob pena de ineficácia de todo sistema de informações instituído.

\subsubsection{Modalidades: indicadores de performance e avaliações}

Como regra, a informação de resultados se expressa por diversos métodos; entretanto, é representada por meio dos indicadores de desempenho (performance 
measures ou performance indicators) ou avaliações (evaluations $)^{47}$. Em um caráter mais amplo, compreende-se que os indicadores são "uma informação que nos permite avaliar aonde vamos e onde estamos, com relação aos nossos objetivos e valores, servindo, inclusive, para avaliar programa de ação e seu alcance"48. Mais especificamente, Jannuzzi ressalta que:

Os indicadores sociais são medidas usadas para permitir a operacionalização de um conceito abstrato ou de uma demanda de interesse programático. Os indicadores apontam, indicam, aproximam, traduzem em termos operacionais as dimensões de interesse definidas a partir de escolhas teóricas ou políticas realizadas anteriormente.

No que concerne ao orçamento por resultados, os indicadores de desempenho realizam o papel fundamental de tornar a alocação de recursos do Estado mais científica e mais próxima da realidade e das suas necessidades. Indicadores de desempenho consistem em classificações ou medidas quantitativas que possibilitam informações sobre a eficiência e efetividade dos programas governamentais ${ }^{49}$.

O Ministério do Planejamento aponta que, no âmbito das políticas públicas, os indicadores constituem-se em ferramentas que permitem a identificação e mensuração de parâmetros que se relacionam a dados, conceitos, fenômenos, problemas e resultados da intervenção na realidade, tendo como finalidade a tradução - expressada de modo mensurável - de certos aspectos de uma dada realidade existente (situação social) ou construída (ação de governo). O indicador torna operacional a observação e avaliação desses aspectos, seja nas situações sociais ou ações de governo.

Nesse sentido, possuem duas funções básicas. A função descritiva, que "consiste em aportar informação sobre uma determinada realidade empírica, situação

47 Curristine aponta ainda que os benchmarks também são uma forma expressiva de informação por resultados adotada entre os países, mas, por propósitos didáticos, cingimos o escopo da abordagem às principais modalidades: os indicadores de desempenho e as avaliações. CURRISTINE, Teresa. Performance information in the budget process: results of the OECD 2005 questionnaire. OECD Journal on Budgeting, v. 5, n. 2, 2005, p. 89.

48 RATTNER, Henrique. Planejamento e bem-estar social. São Paulo: Perspectiva, 1979, p. 151-164.

49 "Performance measures may be defined as ratings or quantitative measures which provide information on the effectiveness and efficiency of public programs (...) Performance measurement is, nevertheless, a very imperfect science, and it is important to any systematic study of performance budgeting to appreciate its limits as well its possibilities.” ROBINSON, M. Performance budgeting: linking funding and results. Basingstoke: Fundo Monetário Internacional/ Palgrave Macmillan, 2007, p. 34. 
social ou ação pública como, por exemplo, a quantidade de famílias em situação de pobreza", e a função valorativa ou avaliativa, que "implica agregar informação de juízo de valor à situação em foco, a fim de avaliar a importância relativa de determinado problema ou verificar a adequação do desempenho de um Programa como, por exemplo, o número de famílias em situação de pobreza em relação ao número total de famílias" ${ }^{50}$.

Tanto os indicadores de desempenho como as avaliações lidam com informações de resultados; no entanto, a informação produzida por cada um deles é distinta. Os indicadores, via de regra, tratam de produtos (outputs), resultados (outcomes), e/ou indicadores de processos. Há, assim, alguns conceitos fundamentais que revolvem a questão e são imprescindíveis para a compreensão dos institutos tratados.

São eles os conceitos de resultado, de produto, de atividade e de insumo ${ }^{51}$. Produtos (outputs) podem ser conceituados com os bens ou serviços resultantes das ações ou instituições estatais, tais como os alunos matriculados em uma escola, os enfermos atendidos em hospitais públicos, entre outras consequências diretamente relacionadas a uma ação praticada pelo Estado.

Resultados (outcomes) são, por sua vez, os impactos pretendidos com a distribuição dos produtos, como, por exemplo, a redução do índice de analfabetismo, o aumento da expectativa de vida, entre outros.

50 Ministério do Planejamento, Orçamento e Gestão. Secretaria de Planejamento e Investimentos Estratégicos - SPI. Indicadores de programas: Guia Metodológico. Brasília: MP, 2010, p. 21-25.

51 "The most fundamental concepts in the conceptual framework of performance management and budgeting are outcomes, outputs, activities and inputs. An output is a good or service provided by an agency to or for an external party. Outcomes are the intended impacts of those outputs. Thus, for example, the medical treatment received by a road accident victim is an output, the intended outcomes of which are the preservation of the patient's life and the minimization of any disability resulting from the accident. Similarly, investigations of crimes are a police output, and reduce crime the intended outcome of that output. Activities are types of work task undertaken in the production of outputs. The delivery of an output generally requires a set of coordinated activities of different types and in different quantities. (The term 'process' is often used more or less synonymously with 'activity', and differences between the two terms are too subtle to be worth dissecting here.) Thus the treatment of the road accident victim may involve a combination of direct treatment activities such as surgery, nursing, and anesthesia, as well as supporting activities such as supplies and facility management. Inputs are resources used in the carrying out of activities to produce outputs (for example, labor, equipment, buildings).” ROBINSON, M. Performance budgeting: linking funding and results. Basingstoke: Fundo Monetário Internacional/Palgrave Macmillan, 2007, p. 26-27. 
Atividades consistem em tarefas empreendidas pela Administração Pública para a viabilização dos produtos; dentro dessa gama, localizam-se a atividade do professor, a assistência médica etc. O termo processo muitas vezes é empregado como sinônimo de atividade nesse ponto.

Por fim, insumos são os recursos empregados na realização dessas atividades: ou seja, são os diversos gastos estatais empregados a fim da obtenção de resultados, tais como os gastos com infraestrutura, mão de obra, manutenção, equipamentos e instrução.

No âmbito da administração por resultados e do orçamento por resultados, também ganham relevância os conceitos de eficiência e efetividade.

Do ponto de vista da informação de resultados, a eficiência está relacionada aos produtos - mais especificamente, ao grau de sucesso no fornecimento um determinado produto ao menor custo possível, mantendo a qualidade constante, estabelecidos os valores de insumos. Efetividade, por outro lado, refere-se ao grau de sucesso dos produtos ou programas em alcançar os resultados esperados. Aumenta-se rentabilidade de um programa estatal se os resultados pretendidos são obtidos com um preço menor.

Os indicadores de resultados (outcomes) apresentam três principais dificuldades: (i) distinguir o impacto de um programa governamental de outros fatores externos; (ii) distinguir os resultados entre diversos programas que compartilham os mesmos objetivos; e (iii) estabelecer parâmetros para analisar programas cujas variáveis sociais não se relacionam com um bom indicador (conforme os requisitos e propriedades indicados no próximo item $)^{52}$. Os indicadores de produtos, por sua vez, são elaborados com maior facilidade, mas apresentam algumas dificuldades quanto à mensuração da qualidade, considerando que o setor público atua com maior expressividade na prestação de serviços do que no fornecimento de bens ${ }^{53}$.

52 Não é simples segregar as consequências diretas da ação estatal de fatores socioeconômicos mais amplos. Alternativas adotadas por diferentes países para esse problema consistem em não separar os resultados de fatores externos ou presumir o que ocorreria sem a intervenção do Estado. Quanto aos programas com objetivos compartilhados, é possível empreender uma análise regressiva, tendo uma base de dados e um intervalo de tempo razoável. No terceiro caso, utilizam-se indicadores aproximados, que muitas vezes são imperfeitos. ROBINSON, M. Performance budgeting: linking funding and results. Basingstoke: Fundo Monetário Internacional/ Palgrave Macmillan, 2007, p. 35.

53 ROBINSON, M. Performance budgeting: linking funding and results. Basingstoke: Fundo Monetário Internacional/Palgrave Macmillan, 2007, p. 37. 
Tendo os diversos indicadores de desempenho em mãos, bem como as informações fornecidas por eles, torna-se necessário, para a interpretação da efetividade e eficiência dos programas públicos, que se realize a análise desses dados. A avaliação consiste justamente nisto: análise para a interpretação dos diversos indicadores de performance e do desempenho dos programas estatais para além dos limites da informação puramente advinda dos indicadores ${ }^{54}$.

Ao tratar dos Desk Evaluations, Marcos Nobrega ${ }^{55}$ destaca os seguintes aspectos para nortear o avaliador: (i) a importância do programa; (ii) a indicação de efetividade e eficiência pela informação de performance; e (iii) a estrutura lógica do programa harmonizada com a concretização dos objetivos.

\subsubsection{Requisitos de viabilidade ou propriedades dos indicadores}

Os requisitos de viabilidade, que também podem ser categorizados como propriedades da informação de resultados, são objeto de inúmeras classificações distintas por parte da doutrina especializada. Autores apontam propriedades divergentes, de modo que se procurará proporcionar uma visão ampla de seus elementos, com ênfase nas principais.

Em uma revisão clássica e abrangente realizada por Grizzle ${ }^{56}$, as propriedades dos indicadores ou requisitos da informação de resultados são os seguintes,

54 "Evaluation necessarily makes use of performance measures, and good evaluation requires good performance measures. The role of analysis is, however, fundamental. Thus a key part of evaluation is consideration of the policy logic of the program in the light of relevant theory - in other words, an assessment of whether theory suggests that one should expect the program to achieve its intended outcomes. For example, the evaluation of an anti-smoking health promotion program should make us of the insights of psychology and marketing theory about what works (and what does note) in changing human behavior. The greater the degree to which outcome measures are ambiguous or lacking, the greater the importance of the analysis of policy logic. Part of such analysis should be consideration of whether there is a compelling theoretical rationale for government to provide a particular service, rather than leaving it to the market (in particular, by reference to the well-developed market failure criteria of economic theory)". ROBINSON, M. Performance budgeting: linking funding and results. Basingstoke: Fundo Monetário Internacional/Palgrave Macmillan, 2007, p. 39.

55 NÓBREGA, Marcos. Orçamento, eficiência e performance budget. In: CONTI, José Maurício; SCAFF, Fernando Facury. Orçamentos públicos e direito financeiro. São Paulo: RT, 2011, p. 723.

56 GRIZZLE, Gloria A. Performance measures for budget justifications. In: MILLER, Gerald J.; HILDRETH, W. Bartley; RABIN, Jack (Coord.). Performance-based budgeting. The American Society for Public Administration, Boulder, Colorado, USA: 2001, p. 358. 
na respectiva ordem de importância: validade, clareza, confiabilidade, relevância para os objetivos e decisões, precisão, sensitividade, custo, facilidade na obtenção dos dados, capacidade de controle, oportunidade, integridade, singularidade, comparabilidade, consistência, credibilidade, utilidade, habilidade de monitorar a qualidade dos dados, privacidade, flexibilidade, representatividade e importância.

Antes dos critérios essenciais da escolha de indicadores, é preciso que se considere a relevância para a agenda governamental. $\mathrm{O}$ indicador deve ser escolhido de acordo com as prioridades governamentais para que seja útil, e, assim, pode-se argumentar que um dos requisitos - ou uma condição preliminar aos requisitos de viabilidade - seja a sua colocação na agenda político-governamental ${ }^{57}$.

Surgem, então, as propriedades relacionadas à adequação técnica dos indicadores. A validade é um requisito unânime nesse quesito, a fim de que as medidas apuradas se aproximem ao máximo do conceito ou objetivo político do qual originam. Assim, o indicador deve ser válido para a finalidade que procurar medir.

É o caso, como bem aponta Jannuzzi, dos indicadores antropométricos ou do padrão de consumo familiar de alimentos em um programa de combate à fome em comparação com uma medida relativa à renda disponível, tal como a proporção de indigentes (como relata o autor "índice de massa corpórea, baixo peso ao nascer ou quantidade de alimentos efetivamente consumidos estão mais diretamente relacionados à nutrição adequada e à desnutrição que à disponibilidade de rendimentos" $)^{58}$. A validade do indicador em relação à demanda política originária, é, portanto, o primeiro requisito a ser observado.

57 Conforme retrata Jannuzzi: “A relevância para a agenda político-social é a primeira e uma das propriedades fundamentais de que devem gozar os indicadores escolhidos em um sistema de formulação e avaliação de programas sociais específicos. Indicadores como a taxa de mortalidade infantil, a proporção de crianças com baixo peso ao nascer e a proporção de domicílios com saneamento adequado são, por exemplo, relevantes e pertinentes para acompanhamento de programas no campo da saúde pública no Brasil, na medida em que podem responder à demanda de monitoramento da agenda governamental das prioridades definidas na área nas últimas décadas”. JANNUZZI, Paulo de Martino. Indicadores para diagnóstico, monitoramento e avaliação de programas sociais no Brasil. Revista do Serviço Público, Brasília, 56 (2):137-160, abr./ jun. 2005, p. 139.

58 JANNUZZI, Paulo de Martino. Indicadores para diagnóstico, monitoramento e avaliação de programas sociais no Brasil. Revista do Serviço Público, Brasília, 56 (2):137-160, abr./jun. 2005, p. 140. 
A confiabilidade do indicador, por seu turno, está atrelada à legitimação de seu uso. O exemplo citado por Jannuzzi nessa hipótese diz respeito à avaliação do nível de violência em uma comunidade - caso em que indicadores relacionados às ocorrências policiais ou mortalidade advinda de causas violentas fatalmente não terão a mesma confiabilidade do que indicadores que podem ser levantados por pesquisas com vítimas ${ }^{59}$.

Por fim, no conjunto de requisitos de adequação técnica, é necessário que os indicadores sejam precisos. Não podem conter qualquer tipo de erros sistêmicos ou predisposições que reflitam uma imagem equivocada do fenômeno que se pretende aferir. Com indicadores válidos, confiáveis e precisos é que se obtém dados úteis.

Superadas as propriedades de ordem técnica, ganham espaço os requisitos de ordem prática. Entre esses, o primeiro e principal é o custo. A informação a ser obtida deve ter um custo razoável, não há sentido em constituir um sistema de informação para medir parâmetros de custo incompatível com o benefício que será obtido a partir do uso desses dados. Consoante, a informação sobre desempenho deve sempre ser econômica, investindo-se no que é realmente necessário.

Clareza também é essencial; o indicador deve ser facilmente interpretado e compreendido tanto por operadores técnicos, como por leigos na matéria. A informação também deve poder ser obtida facilmente, para que o sistema não fique complexo em demasia. Outro ponto é a controlabilidade: é importante medir aquilo que está sob o controle da administração, pois a medida de fatos que estejam fora do controle pode ser prejudicial (ocasionalmente, há medidas de difícil controle que são importantes, como a demanda esperada por serviço em determinados cálculos de eficiência e efetividade; nesses casos, o ideal é que se demonstre que se trata de um indicador que, de fato, não está sob controle da $\left.\operatorname{administração~}{ }^{60}\right)$.

A partir desse diagnóstico, e tendo em vista as propriedades mais relevantes dos indicadores de resultados, Grizzle propõe o seguinte quadro-modelo ilustrativo para a sua seleção, que se adota como proposta para compreensão dos requisitos gerais para a formulação dos indicadores de performance:

59 JANNUZZI, Paulo de Martino. Indicadores para diagnóstico, monitoramento e avaliação de programas sociais no Brasil. Revista do Serviço Público, Brasília, 56 (2):137-160, abr./jun. 2005, p. 140.

${ }^{60}$ Cf. ARNOLD, W. G. Performance budgeting: what works, what doesn't. Vienna: Management Concepts, 2008. 
Tabela 2 Identificação dos requisitos de viabilidade dos indicadores de resultados, baseado em Grizzle, com adaptações do Autor ${ }^{61}$.

\begin{tabular}{|c|}
\hline I. ADEQUAÇÃO TÉCNICA \\
\hline A. Validade \\
\hline A medida representa logicamente o conceito a ser medido? \\
\hline 1. Integralidade \\
\hline A medida abrange a integralidade do conceito? \\
\hline 2. Singularidade \\
\hline A medida representa algum conceito não abrangido por outra medida neste conjunto? \\
\hline B. Confiabilidade \\
\hline $\begin{array}{l}\text { Se a mensuração for repetida, os resultados serão idênticos? Há flutuações nas características a serem mensu- } \\
\text { radas, mudanças em fatores pessoais ou situacionais transitórios, ou inconsistentes com o processo de mensu- } \\
\text { ração que causam variação na mensuração obtida? }\end{array}$ \\
\hline C. Precisão \\
\hline A mensuração é livre de erros sistêmicos ou predisposições? \\
\hline II. PRATICABILIDADE \\
\hline A. Custo \\
\hline Quanto a coleta e análise de dados irá custar? \\
\hline B. Facilidade na coleta de dados \\
\hline Qual o grau de facilidade ou dificuldade em obter os dados necessários para realizar a mensuração? \\
\hline III. REQUISITOS INDEPENDENTES DO USUÁRIO-UTILITÁRIO \\
\hline A. Comparabilidade \\
\hline Esta medida pode ser utilizada para comparar diferentes programas com outros? \\
\hline B. Sensitividade \\
\hline $\begin{array}{l}\text { O poder discriminatório do processo de mensuração é suficiente para capturar as variações que ocorrem no } \\
\text { objeto, evento ou situação sendo medida? }\end{array}$ \\
\hline
\end{tabular}

${ }^{61}$ GRIZZLE, Gloria A. Performance measures for budget justifications. In: MILLER, Gerald J.; HILDRETH, W.; Bartley; RABIN, Jack (Coord.). Performance-based budgeting. The American Society for Public Administration. Boulder, Colorado, USA: 2001, p. 359. 


\begin{tabular}{|l|}
\hline C. Clareza \\
\hline O significado da medida pode ser compreendido? \\
\hline \multicolumn{1}{|c|}{ IV. REQUISITOS DEPENDENTES DO USUÁRIO-UTILITÁRIO } \\
\hline A. Relevância para as decisões \\
\hline $\begin{array}{l}\text { A medida fornece informações necessárias para realizar uma decisão sobre o desempenho de um programa ou } \\
\text { entidade? }\end{array}$ \\
\hline B. Oportunidade \\
\hline $\begin{array}{l}\text { As mudanças nos objetos, eventos, ou situações sendo mensuradas são refletidas de maneira rápida o suficien- } \\
\text { te nas medidas para se tornarem disponiveis antes que a decisão seja tomada? }\end{array}$ \\
\hline C. Controlabilidade \\
\hline $\begin{array}{l}\text { Em que medida pode o usuário da medida afetar as mensurações, considerando que recursos estejam disponí- } \\
\text { veis para isso? }\end{array}$ \\
\hline
\end{tabular}

\subsubsection{Observações finais e critério gerais para orientar os sistemas de informação}

Tecidas essas principais considerações sobre a informação de desempenho, e à luz da orientação estabelecida no FMI pelo financista Marc Robinson mencionada acima, parece que, na instituição do orçamento por resultados, os dois princípios-condutores da informação de desempenho a serem sempre colocados em foco pelos gestores financeiros, formuladores de políticas públicas e da política orçamentária e juristas no campo do direito financeiro são a economia e a utilidade.

A informação sobre desempenho deve ser útil para os processos decisórios no âmbito da administração das políticas sociais e do erário; para informar o cidadão acerca do desempenho da atividade governamental e do grau de realização das metas estabelecidas, indicando as prioridades perseguidas pelo Estado; para orientar os agentes envolvidos com o programa e atividade que estão sendo avaliados no sistema de informação.

Para ser útil, no sentido amplo, a informação sobre desempenho deve observar, por evidência, os requisitos de viabilidade apontados. Deve ser válida, clara, compreensível, confiável, comparável e precisa. As avaliações realizadas também devem estar inseridas no contexto adequado, de maneira a refletir uma perspectiva útil sobre a análise dos indicadores.

Além da utilidade, a condução dos sistemas de informação deve ser econômica, a fim de que se tenha viabilidade no seu exercício - a instituição e manutenção de um sistema econômico inviável está fadada ao fracasso. 
A informação sobre desempenho e o custo-benefício será sempre avaliada pelos atores envolvidos nos processos de fixação de diretrizes, coletas, monitoramento, avaliação e controle dos dados, de maneira a garantir a sustentabilidade do sistema. Afinal, busca-se justamente alcançar a eficiência na alocação dos recursos financeiros do Estado - e não o seu desnecessário dispêndio.

A harmonia entre economia e utilidade na produção da informação de resultados é um norte que pode facilitar a seleção de indicadores com amparo nos critérios de efetividade e eficiência que são o verdadeiro paradigma do desempenho.

\subsection{INCORPORANDO A INFORMAÇÃO DE RESULTADOS NO PROCESSO ORÇAMENTÁRIO}

\subsubsection{Estrutura dos programas e classificação orçamentária}

No âmbito do orçamento por resultados, a estrutura dos programas e sua classificação é redimensionada para que o foco seja dirigido aos produtos e resultados, de forma que resultados e impactos passam a ser o rumo da programação e do planejamento. Evidentemente, os gastos devem ser orientados por programas (orçamento-programa), sendo este um passo pré-constitutivo para a formulação dos arranjos estruturais no orçamento por resultados.

É o programa que viabiliza a conexão dos gastos com os resultados esperados, fixados nas metas, e com os objetivos das políticas públicas. De igual maneira, o quadro de contas nos sistemas de informações financeiras deve observar classificação equivalente, a fim de relatar os gastos com base nos programas ${ }^{62}$. A estrutura dos programas tem papel de protagonismo na ligação entre o planejamento-financeiro e o planejamento estratégico, como bem aponta Diamond:

Desta maneira, a estrutura de programas é a conexão entre o orçamento e o planejamento estratégico geral que reflete o quadro de políticas para as operações do governo. De acordo, a estrutura dos programas é muito mais que uma maneira de classificar gastos, mas deve ser vista como uma ferramenta

62 "Performance informed budgeting requires expenditure to be categorized by the program that it supports, rather than simply economic and administrative arrangements. (Robinson this chapter). This enables expenditures to be clearly linked to program results and government policy objectives. The development of a program-based classification of the budget is therefore often a key tool in the implementation of PIB. In addition, the chart of accounts contained in the financial management information system needs an equivalent classification to enable reporting of actual expenditures on a program-basis." BANCO MUNDIAL. Results, performance budgeting and trust in government. Washington D.C.: The International Bank for Reconstruction and Development/The World Bank, 2010, p. 126. 
de análise política. É uma forma de considerar o que deve ser custeado, em que nível os fundos devem ser aplicados, e qual o impacto político dos fundos aplicados ${ }^{63}$.

A estrutura dos programas é basicamente o modo com que se descreve o plano de gastos do orçamento em termos de objetivos. De tal maneira, é importante que a estrutura dos programas seja fundamentada em uma visão estratégica ampla, que permita a descrição sobre como as atividades governamentais previstas contribuem para atingir os objetivos da política nacional. Como bem salienta o autor ${ }^{64}$ :

Para usar a linguagem do planejamento estratégico, os objetivos nacionais ou áreas estratégicas de resultados são traduzidas em áreas chave de resultados detalhadas e totalmente custeadas, que são responsáveis por unidades governamentais específicas.

No tocante à estrutura dos programas, o orçamento por resultados dá um passo adiante à estrutura tradicional, apresentando os propósitos e objetivos para os quais os recursos são aplicados, o custo dos programas e atividades associadas para atingir tais objetivos, e os produtos a serem produzidos ou serviços a serem entregues em cada programa, observando um elo baseado em resultados ${ }^{65}$. Além dos programas e atividades, previstos no orçamento-programa tradicional, a estrutura do orçamento por resultados ocupa-se também dos objetivos de desempenho, resultados, impactos e alcance dos programas.

A cadeia de resultados pode ser observada, a título exemplificativo, da seguinte maneira: (i) Objetivos do Programa; (ii) Insumos; (iii) Insumos Intermediários; (iv) Produtos; (v) Resultados; (vi) Impactos; e (vii) Alcance.

63 "In this way, the program structure is the link between the budget and the overall strategic planning that reflects the policy framework for government operations. Accordingly, the program structure is much more than a way of classifying expenditures but should be viewed as a tool of policy analysis. It is a way to consider what should be funded, the level of the funds that should be applied, and the policy impact of the funds applied.” DIAMOND, J. From program to performance budgeting: the challenge of emerging market economies. Washington D.C.: International Monetary Found, 2003, p. 12.

64 "To use the language of strategic planning, the national objectives or 'strategic result areas' are translated into detailed and fully costed 'key result areas' which are the responsibility of specific government units. The latter should then formulate the required detailed implementation plans required for preparing the agency's budget bid.” DIAMOND, J. From program to performance budgeting: the challenge of emerging market economies. Washington D.C.: International Monetary Found, 2003, p. 11.

65 SHAH, Anwar; SHEN, Chunli. A primer on performance budgeting. In: SHAH, Anwar (Coord.). Budgeting and budgetary institutions. Washington: The World Bank, 2007, p. 143. 
Shah e Shen ilustram o conceito citando exemplo na política de educação ${ }^{66}$ :

1. Objetivos do Programa - Aprimorar a quantidade, qualidade e acesso aos serviços educacionais.

2. Insumos - Gasto educacional por idade, gênero, área urbana/rural, gasto por série escolar e número de professores, funcionários, instalações ferramentas e livros.

3. Insumos intermediários - Matrículas, coeficiente de estudantes por professor e tamanho das classes.

4. Produtos - Notas atingidas, índice de formação de alunos e de abandono.

5. Impactos - Nível educacional da população, engajamento cívico, competitividade internacional.

6. Alcance - Vencedores e perdedores dos programas governamentais.

Com o uso dos recursos dirigido à concretização das metas e objetivos, o orçamento por resultados assegura maior flexibilidade nas decisões de gasto porque, em comparação ao orçamento tradicional - voltado unicamente à previsão de receitas e despesas - a ênfase não reside nos gastos específicos a serem realizados, nem mesmo apenas no gasto com programas e atividades. Os objetivos e metas de desempenho são mais amplos, compreendendo as prioridades estatais, e avançam as possibilidades técnicas de decisão e a análise das políticas de governo.

A estrutura de programas do modelo de orçamento por resultados é utilizada amplamente, inclusive no Brasil, em diversos programas de nível federal, especialmente nas políticas sociais. É fundamental que se tenha, entretanto, clareza e adequação nas metas fixadas, e que a estrutura voltada aos resultados não seja apenas uma falácia incorporada no orçamento, mas uma efetiva demonstração da realidade e da projeção exigível dos objetivos governamentais para cada programa.

Por isso, a singela reforma na estrutura dos programas do orçamento e na classificação orçamentária não é suficiente para estabelecer um modelo de orçamento de desempenho que, como já se viu, caracteriza-se principalmente com a efetiva utilização da informação de resultados nos processos de tomada de decisão do ciclo orçamentário. É elemento indispensável, de fato, para que a informação de resultados seja incorporada no processo orçamentário, mas sua adoção isolada não garante, de nenhuma forma, que o orçamento passe a ser de fato orientado a resultados.

66 SHAH, Anwar; SHEN, Chunli. A primer on performance budgeting. In: SHAH, Anwar (Coord.). Budgeting and budgetary institutions. Washington: The World Bank, 2007, p. 144. 
De todo modo, essa guinada na estrutura dos programas é deveras relevante, inclusive para a formulação de políticas públicas. Conforme destaca Ana Cláudia N. Capella ${ }^{67}$, "o modo como os problemas são conceituados no processo de formulação de politicas e as maneiras pelas quais as alternativas são apresentadas e selecionadas são questões fundamentais para a compreensão da dinâmica da ação estatal". Não há dúvida de que a reflexão se aplica também aos programas do orçamento público.

\subsubsection{Sistema de mensuração de desempenho}

A incorporação da informação de resultados no processo orçamentário pressupõe o estabelecimento de um sistema de mensuração de desempenho que seja projetado com integração no orçamento. A existência de sistemas isolados, como no caso de políticas públicas, não é suficiente para integrar os dados de desempenho no processo orçamentário. É preciso que, no modelo de análise de desempenho instituído, estabeleça-se uma ligação direta com o planejamento financeiro-orçamentário. Nada obsta, entretanto, que sistemas já existentes sejam utilizados, o que facilita o processo de coleta de informações.

A inserção de metas e indicadores no orçamento é realizada via de regra por uma combinação entre produtos e resultados.

A concentração apenas nos produtos pode dispersar o foco dos impactos que se intenciona com os programas, perseguindo-se resultados quantificáveis e esquecendo-se dos mais difíceis de serem medidos. Ao mesmo tempo, a incorporação apenas de resultados também não é recomendada, pois "enquanto os resultados incorporam um foco mais amplo no impacto dos programas na sociedade e têm maior apelo aos políticos e ao público, eles são muito difíceis de mensurar"68.

Deve-se ter em vista que a informação de desempenho é distinta das informações de natureza financeira e todas as peculiaridades precisam ser levadas em conta na sua introdução ao orçamento, não havendo solução única para todo o plexo de programas governamentais. À evidência, os indicadores são mais facilmente aplicáveis aos programas com resultados tangíveis.

${ }^{67}$ CAPELlA, Ana Cláudia N. Perspectivas teóricas sobre o processo de formulação de políticas públicas. Revista Brasileira de Informações Bibliográficas em Ciências Sociais (BIB), n. 61, 2006, p. 126.

68 "While outcomes incorporate a wider focus on the impact of programmes on society and have greater appeal to politicians and the public, they are very difficult to measure." CURRISTINE, T. Governance performance: lessons and challenges. OECD Journal on Budgeting, Paris: OECD, v. 5, n. 1, 2005, p. 134. 
A respeito, a OCDE define três tipos distintos de programas para esse propósito: (i) programas tangíveis de serviços individuais; (ii) programas intangíveis de serviços individuais; e (iii) programas intangíveis de serviços ideais. A primeira categoria, que envolve a entrega de bens e serviços tangíveis com produtos observáveis (ex. programas de emissão de passaportes e carteiras de motorista), é a mais simples de ser incorporada ${ }^{69}$.

Em serviços intangíveis, como saúde e educação, os sistemas de mensuração de desempenho são mais complexos, mas possíveis de serem introduzidos. Apesar de desafiadoras, essas são as áreas em que a experiência internacional mais tem concentrado a utilização de mecanismos do orçamento por resultados, tendo em vista a necessidade e a pressão social para a entrega de melhores níveis de desempenhos para a população nesses campos vitais para a sociedade.

De acordo com o Banco Mundial, os passos básicos para estabelecer um sistema de informação de desempenho compreendem: a especificação dos objetivos do programa no formato de produtos e resultados (o que, como se viu, pode-se integrar na estrutura dos programas orçamentários), a identificação da lógica interventiva do programa e a informação de desempenho que deverá capturar em que medida os objetivos serão atingidos.

Assim, a integração desses dados nos programas orçamentários pode ser deveras relevante para aferir os resultados atingidos nas avaliações e instruir futuras decisões, a partir dos dados de execução orçamentária.

A identificação dos indicadores a serem associados aos programas tem como primeiro passo essencial a especificação explícita dos objetivos-chave buscados pelo governo. Primeiro, elege-se os resultados para cada categoria de programa o que, segundo Robinson, é um exercício que pode ser combinado com a elaboração da estrutura de programas de cada ministério ou agência ${ }^{70}$.

69 "Three types of programme can be distinguished: tangible and non-tangible individually tailored services, and non-tangible ideal services (OECD, 2001). Performance indicators are more easily applied in programmes which involve the delivery of a tangible good or service with observable outputs such as issuing passports or driving licenses or collecting taxes. It is easier to create reliable unit cost measures for this type of activity. It is possible, although more difficult, to design performance measures for complex services to individuals such as education and health care. Performance indicators are very difficult to apply to activities such as policy advice where the service is non-tangible and outcomes are not visible." CURRISTINE, T. Governance performance: lessons and challenges. OECD Journal on Budgeting, Paris: OECD, v. 5, n. 1, 2005, p. 145.

70 "Expressed differently, it is necessary to clearly state the desired outcomes for each of the major categories of government outputs. The articulation of intended outcomes is an exercise which can usefully be combined with the development of a draft program structure for each ministry/ 
Com os resultados escolhidos, o autor retrata que o desenvolvimento dos indicadores para o sistema de mensuração de desempenho pode ser compreendido em três estágios. O primeiro estágio é a criação de boas medidas de quantidade de produtos e atividades. O segundo estágio corresponde à unificação dos sistemas de informação de desempenho com sistemas de contabilidade para desenvolver medidas de custo de programas e produtos chave (sistema de mensuração de custos). Enfim, o terceiro estágio diz respeito à observação das áreas mais desafiadoras de medir a qualidade dos produtos e resultados ${ }^{71}$.

Cabe ainda destacar que o desenvolvimento do sistema de informação de desempenho e sua integração no processo orçamentário consiste em um projeto de médio e longo prazo, cujos benefícios podem ser observados progressivamente $^{72}$. A sua introdução no processo orçamentário, de tal forma, também será gradativa, observando o desenvolvimento e o alcance do sistema de informação: de início, contemplando apenas a integração das informações nos dados do orçamento; e daí evoluindo até que tais informações possam ser de fato empregadas pelos tomadores de decisão no processo orçamentário.

\subsubsection{Sistema de determinação de custos}

Além do sistema de mensuração de desempenho, é de igual importância o estabelecimento do sistema de determinação do custo de programas e produtos, essencial para permitir a análise de custo-benefício e da relação entre resultados entregues e gasto realizado. Sobre esse tópico, Marcos Nóbrega afirma que, atualmente, se observa grande deficiência nos sistemas de controle interno da Administração Pública, com quase total desconhecimento dos custos dos serviços prestados, dificultando a melhora da qualidade dos serviços públicos.

Segundo Nóbrega, o conceito de sistema de custos não envolve apenas a contabilidade, como também os indicadores de desempenho sobre a qualidade dos

agency”. ROBINSON, M. Results information. ROBINSON, M. (Org.). Performance budgeting: linking funding and results. Basingstoke: Fundo Monetário Internacional/Palgrave Macmillan, 2007, p. 40.

71 ROBINSON, M. Results information. In: ROBINSON, M. (Org.). Performance budgeting: linking funding and results. Basingstoke: Fundo Monetário Internacional/Palgrave Macmillan, 2007, p. 41.

72 "By its nature, the development of performance information for performance budgeting - and for other 'managing-for-results' uses - is a medium to long-term project. It is however, a project which can yield some benefits relatively quickly and others progressively over time". ROBINSON, M. Results information. In: ROBINSON, M. (Org.). Performance budgeting: linking funding and results. Basingstoke: Fundo Monetário Internacional/Palgrave Macmillan, 2007, p. 42. 
serviços, por exemplo: (i) número de crianças matriculadas e custo por aluno; (ii) número de leitos e custo por paciente nos hospitais públicos; (iii) custo do transporte escolar gratuito; e (iv) custo da merenda escolar etc. ${ }^{73}$

O principal ponto a ser levado em conta sob esse prisma é que a ênfase em produtos e resultados dada pelo orçamento de resultados de nenhuma forma elimina a premente necessidade de identificar insumos e recursos que permanecem sendo os principais elementos do orçamento anual e da contabilidade. Só é possível otimizar a alocação de recursos e aplicar melhor o dinheiro público conhecendo os custos das atividades e programas aplicados para atingir os objetivos e resultados; e, a partir desses custos empenhados, consegue-se apurar a eficiência e economicidade das despesas.

Sob essa perspectiva, o sistema de aferição dos custos é de igual importância ao sistema de mensuração de desempenho, porque um depende do outro a fim de possibilitar a análise dos recursos atribuídos e buscar decisões orçamentárias mais eficientes e eficazes nos processos de planejamento e execução.

O principal para a análise de priorização do gasto e custo-benefício no âmbito geral do governo, de fato, é a determinação dos custos dos programas (program costing), uma vez que no orçamento as decisões de prioridade orçamentária são focadas em como distribuir as receitas entre os programas, de tal modo que o ponto de partida é medir o custo de tais programas para permitir a comparação, seja ela informal, seja ela sistemática. $\mathrm{O}$ ajuste fino do gasto, por sua vez, se dá nos componentes desagregados dos programas no âmbito dos órgãos e agências, que também demandam a informação de $\operatorname{custos}^{74}$.

${ }^{73}$ NÓBREGA, Marcos. Orçamento, eficiência e performance budget. In: CONTI, José Maurício; SCAFF, Fernando Facury. Orçamentos públicos e direito financeiro. São Paulo: RT, 2011, p. 693-729.

${ }^{74}$ A observação é de Robinson: "For expenditure prioritization purposes, it is program costing which is usually seen as of primary importance. In other words, with expenditure prioritization decisions viewed as a matter of deciding how to allocate money between programs, the starting point is to measure program costs so as to permit a comparison - be it informal or more systematic - between program costs and benefits. The approach is based upon the widely-held assumption that at the level of the government-wide budget, it is in general only practical to set priorities in terms of the broad categories of expenditure which programs represent. From this perspective, the appropriate place for more detailed expenditure prioritization is internally within agencies, and it follows that for this purpose agencies will require cost information for more disaggregated program components (for example, sub-programs)." ROBINSON, M. Cost Information. In: ROBINSON, M. (Org.). Performance budgeting: linking funding and results. Basingstoke: Fundo Monetário Internacional/Palgrave Macmillan, 2007, p. 59. 
$\mathrm{Na}$ mesma linha de raciocínio, Diamond salienta que, para a estrutura de programas ser implementável, há de haver mecanismos adequados a fim de custear os programas, de sorte que o produto dos programas possa ser relacionado ao seu custo orçamentário, e, por último, aos seus benefícios, de modo a julgar o desempenho do programa.

O autor ainda afirma que, seja qual for o critério utilizado, esses devem ser especificados dentro de um sistema de custos que cubra todo o governo, produzindo informações precisas sobre os programas, não sendo por demais complexo ou demandando excesso de recursos ${ }^{75}$.

Robinson, no seu turno, relata que o desenvolvimento da informação de custos não se faz somente com a busca da gama mais completa de informações dos custos para atingir resultados, empregando metodologia de contabilidade sofisticada e precisa. A estratégia de custo de informações deve "ser guiada por escolhas sobre a forma de orçamento por resultados sendo implementada, porque diferentes formas de orçamento por resultados têm diferentes requisitos de informação" ${ }^{76}$.

Por fim, note-se que o sistema de mensuração de custos deve ser orientado pela economia, de maneira que o custo de sua instituição deve ser ponderado em equilíbrio com os benefícios daí advindos. É preciso cotejar os benefícios trazidos para os processos de decisão pelos melhores sistemas de determinação de custos em contraste com os recursos que são exigidos para a sua manutenção; afinal, não é razoável que se tenha um sistema caro sem o consequente aproveitamento.

\subsubsection{Planejamento, financiamento e responsabilidade institucional}

Para que a informação de resultados seja devidamente incorporada no processo orçamentário e utilizada nos processos de decisão, sua integração deve ocorrer em todas as etapas do ciclo orçamentário, compreendendo o planejamento-financeiro, execução e controle do orçamento. De igual modo, surte efeito nas

75 DIAMOND, J. From program to performance budgeting: the challenge of emerging market economies. Washington D.C.: International Monetary Found, 2003, p. 19-20.

76 "Cost information strategy must, rather, be guided by choices about the form of performance budgeting being implemented, because different forms of performance budgeting have different information requirements. It must also be guided by recognition of the high marginal cost of better cost information and their consequent need to strike a balance between these costs and the decision-making benefits of better-quality information." ROBINSON, M. Cost information. In: ROBINSON, M. (Org.). Performance budgeting: linking funding and results. Basingstoke: Fundo Monetário Internacional/Palgrave Macmillan, 2007, p. 59. 
negociações orçamentárias para financiamento dos programas e na responsabilidade institucional do ponto de vista orçamentário.

No âmbito das negociações orçamentárias, a utilização da informação de desempenho concede um caráter técnico para as discussões de planejamento e financiamento de ministérios e programas, elevando a ênfase no estabelecimento de metas e mensuração de resultados.

Com os dados de desempenho integrados nos processos orçamentários, os atores políticos que precisam de recursos têm na informação de desempenho um novo elemento em jogo para pautar as discussões nas decisões de financiamento. Há grande debate sobre como deve ser a ligação entre a informação de desempenho e o financiamento e raramente os dados de resultados são usados para determinar as alocações de recurso.

Conforme relatório da OCDE, alguns países inclusive possuem uma abordagem formal que exige de todos ministérios a apresentação de planos de desempenho para o Ministério das Finanças, em conjunto com as propostas de gasto, enquanto outros países possuem uma abordagem não tão geral, aplicando os planos de desempenho e resultados apenas para alguns ministérios e setores ou apenas para os que pedirem financiamento para novos programas ou recursos adicionais para os programas já existentes ${ }^{77}$.

O financiamento dos programas está também ligado ao planejamento da atividade estatal. A integração da informação de resultados no processo orçamentário passa a orientar o planejamento-financeiro do Estado a partir dos critérios de resultados, revelando, por conseguinte, maior transparência, responsabilidade, clareza e realismo nos objetivos a serem perseguidos, o que também resulta em uma avaliação eficaz e eficiente sobre a concretização desses objetivos.

Em consonância com essa observação, o Banco Mundial destaca que a "a ênfase em resultados encoraja maior ênfase no estabelecimento transparente de objetivos no planejamento, e fornece informação sobre o que está funcionando e o que não está”78.

77 ORGANISATION FOR ECONOMIC CO-OPERATION AND DEVELOPMENT. Performance budgeting in OECD countries. Paris: OECD, 2007, p. 43.

78 "Despite the challenges, the potential benefits from the use of performance information in the budget process appear significant. The emphasis on results encourages greater emphasis on the transparent setting of objectives in planning, and provides information on what is working and what is not. Legislatures and the public are also likely to continue to demand results (and information to assess it) for their taxes." WORLD BANK. Results, performance budgeting and trust in government. Washington D.C.: The International Bank for Reconstruction and Development/The World Bank, 2010, p. 30. 
A ênfase em resultados, consequentemente, implica também um destaque do processo de planejamento, auxiliando na compreensão e melhor entendimento das metas e prioridades do governo e em como os programas contribuem para atingir tais metas.

É no palco do planejamento que as metas serão fixadas, a partir da avaliação dos resultados atingidos - estágio no qual os rumos da atividade do Estado serão fixados, à luz de critérios tangíveis de resultados a serem alcançados em harmonia com o macro plano constitucional de direitos e com o projeto democrático de governo. A ênfase em resultados dá força para o planejamento ${ }^{79}$.

Há também mecanismos interessantes no planejamento que também são frequentemente relacionados ao orçamento por resultados, como por exemplo o Banco de Projetos, visando a escolha dos projetos de investimento que melhor se adequem à relação custo-benefício de acordo com o programa político estatal ${ }^{80}$.

Além disso, a informação por resultados integrada no processo orçamentário impacta a responsabilidade institucional de gestores, planejadores e agentes da Administração Pública nos processos de planejamento e financiamento.

Nesse ponto, a OCDE relata que os Ministérios de Finanças podem utilizar a informação de resultados justamente para tornar agências e ministérios responsáveis pelo desempenho, inclusive com mecanismos de incentivos e sanções ${ }^{81}$. Não

79 "OECD countries have reported a number of benefits from using performance information, not least the fact that it generates a sharper focus on results within government. The process also provides more and better understanding of government goals and priorities and on how different programs contribute to them. At the same time, performance information encourages greater emphasis on planning and offers a good indication of what is working and what is not. This tool also improves transparency, by providing more and better information to legislatures and the public." WORLD BANK. Results, performance budgeting and trust in government. Washington D.C.: The International Bank for Reconstruction and Development/The World Bank, 2010, p. 83.

80 Sistema como esse foi proposto em Parecer da Comissão de Assuntos Econômicos do Senado Federal sobre o Projeto de Lei n. 229 de 2009, relatado pelo Senador Ricardo Ferraço: “A exemplo de boas práticas internacionais na gestão dos investimentos públicos, propomos a criação de Sistema Nacional de Projetos de Investimento (SNIP) que consubstanciará os sistemas dos entes da Federação com mais de 200 mil habitantes. O SNIP tem como objetivo melhorar a eficiência e eficácia no uso dos recursos públicos, atribuindo-os a iniciativas de investimentos que gerem maior rentabilidade econômica e social, em conformidade com as orientações das políticas do Governo".

81 ORGANISATION FOR ECONOMIC CO-OPERATION AND DEVELOPMENT. Performance budgeting in OECD Countries. Paris: OECD, 2007, p. 44. 
obstante, a responsabilização demanda a existência de informações adequadas de desempenho que permitam julgar a performance a partir dos resultados exibidos ${ }^{82}$.

\subsubsection{Mecanismos para promover o desempenho, incentivos e sanções financeiras}

A simples integração da informação de resultados no processo orçamentário não basta para que o desempenho estatal venha a ser aprimorado; essa informação precisa ser utilizada e, assim, vêm à tona os mecanismos para promover o desempenho que auxiliam em promover a performance das atividades da Administração Pública.

Com efeito, conforme relata Hassan Ouda, o aprimoramento da eficiência, da qualidade e da efetividade dos gastos públicos é alcançado por meio de decisões que determinam a realocação e reatribuição dos recursos, o desenvolvimento de métodos de trabalho aprimorados, a adoção de práticas otimizadas e o ajustamento das prioridades ${ }^{83}$.

Ao examinar o uso da informação de desempenho, Curristine relata que os usos mais comuns observados são os seguintes: (i) nas decisões orçamentárias, a informação de desempenho é utilizada em conjunto com outras informações para determinar a alocação dos recursos; (ii) com função sinalizadora, para monitorar o desempenho de organizações e agências e evidenciar os casos em que medidas interventivas são necessárias; (iii) avaliações do gasto conduzidas pelos ministérios em exercícios de revisão do gasto; e (iv) administração dos programas pelos ministérios responsáveis ${ }^{84}$.

É fundamental que existam, portanto, mecanismos a fim de estimular o desempenho para toda a gama de atores envolvidos no processo orçamentário e na Administração Pública, de maneira a facilitar a integração da informação de resultados como verdadeira rotina orçamentária. Desses mecanismos, a fixação

82 "Improved accountability is dependent on adequate information to judge performance. There is no point in designing and implementing a program structure if there is no information for their evaluation. The design of programs should take into account the practicality of constructing a comprehensive and regular information and reporting system to provide relevant data in a timely manner." DIAMOND, J. From program to performance budgeting: the challenge of emerging market economies. Washington D.C.: International Monetary Found, 2003, p. 19.

83 OUDA, Hassan A. G. Suggested framework for implementation of performance budgeting in the public sector of developing countries with special focus on Egypt. In: 13th Biennial CIGAR Conference, 2011.

${ }^{84}$ CURRISTINE, T.; JOUMARD, I.; LONTI, Z. Improving public sector efficiency: challenges and opportunities. OECD Journal on Budgeting, Paris: OECD, 2007, v. 7, n. 1, p. 18. 
de incentivos e sanções financeiras do ponto de vista orçamentário é a medida mais amplamente utilizada.

Com esse método, são estabelecidos incentivos (prêmios) e sanções financeiras no orçamento de acordo com o desempenho dos ministérios, organizações e agências, dentro de limites razoáveis. Procura-se recompensar no orçamento aqueles que atingem suas metas, enquanto são estabelecidas sanções aos que apresentarem desempenho negativo.

Hassan Ouda sustenta que, para uma entidade do setor público ser bem-sucedida, é essencial que se tenham medidas de sucesso cuidadosamente definidas. Isso envolve um processo estruturado para a conexão entre os objetivos do governo a fatores críticos de sucesso e a medidas de desempenho associadas.

Nesse sentido, o comportamento dos gestores públicos estará diretamente ligado aos critérios de desempenho sobre o qual a sua remuneração é fixada. Há, dessa forma, um valor motivacional na vinculação entre a remuneração e a análise de desempenho ${ }^{85}$.

Não obstante, a grande dificuldade desses incentivos e sanções revela-se na própria natureza da decisão orçamentária, envolvida por problemas e contextos de elevada complexidade, inclusive nos aspectos institucionais e políticos.

Curristine, Joumard e Lonti apontam alguns dos desafios dos incentivos e sanções advindos da análise da informação de desempenho.

Segundo os autores, apesar da atração intuitiva de recompensar o bom desempenho e sancionar o desempenho ruim, adotar esse tipo de medida de forma automática pode caracterizar cenários problemáticos, pois (i) não se levaria em conta as prioridades do governo e as limitações orçamentárias; (ii) os indicadores de desempenho não explicam as causas subjacentes da performance ruim; e (iii) o desempenho em qualquer ano é influenciado por uma variedade de fatores, internos e externos, que podem estar fora do controle do órgão avaliado. Além disso, é preciso levar em consideração se a qualidade da informação de desempenho é relevante para que possa ser utilizada em decisões de incentivos e sanções ${ }^{86}$.

A despeito dos desafios, o mecanismo é relevante e possui notável capacidade indutora de comportamentos no âmbito do setor público para estimular o melhor desempenho, caso o sistema seja estabelecido com critérios claros, razoáveis e

85 OUDA, Hassan A. G. Suggested framework for implementation of performance budgeting in the public sector of developing countries with special focus on Egypt. In: 13th Biennial CIGAR Conference, 2011, p. 24.

86 CURRISTINE, T.; JOUMARD, I.; LONTI, Z. Improving public sector efficiency: challenges and opportunities. OECD Journal on Budgeting, Paris: OECD, v. 7, n. 1, 2007, p. 16-17. 
úteis para uma avaliação adequada, dentro de padrões auditáveis que garantam a segurança do modelo instituído.

Por isso, é de extrema importância ter cautela com a possibilidade de incentivos perversos, que estimulem as organizações públicas a fraudar e manipular dados com o objetivo de situar em melhor colocação nas avaliações de desempenho.

Sob essa perspectiva, é ideal que se priorize os incentivos em vez das sanções, pois "é politicamente irracional esperar que agências forneçam informações objetivas se estas serão usadas para cortar os seus programas" ${ }^{87}$.

\subsubsection{Flexibilidade financeira e flexibilidade gerencial}

A incorporação da informação de resultados no processo orçamentário também demanda que se mitigue a ênfase em insumos, privilegiando a ênfase em produtos e resultados - o que corresponde a atribuir maior flexibilidade financeira aos destinatários das dotações orçamentárias, de sorte que os recursos sejam atribuídos para alcançar objetivos e não para a aquisição de insumos previamente eleitos no orçamento.

A flexibilidade financeira está atrelada também a flexibilidade gerencial, sendo uma inalcançável sem que se tenha a outra, uma vez que não é possível que se tenha liberdade para administrar sem ter certa liberdade para gastar - e não há liberdade para gastar que não corresponda a uma liberdade para administrar, tendo em vista as atividades do Estado.

Não se trata de igualar a administração das atividades públicas com a administração das atividades privadas; mas de flexibilizar as potencialidades administrativas e financeiras dos gestores, sob o paradigma da incorporação de critérios de desempenho no processo orçamentário e administrativo, vertendo o foco do planejamento e controle para os produtos e resultados da gestão, e não para os insumos e atividades que demandam gasto.

Na lição da OCDE:

A introdução de metas de produtos e/ou resultados como um sistema de controle da administração demanda controles de insumo relaxados a fim de dar aos administradores liberdade para usar recursos para atingir resultados e melhorar o desempenho ${ }^{88}$.

${ }^{87}$ CURRISTINE, T.; JOUMARD, I.; LONTI, Z. Improving public sector efficiency: challenges and opportunities. OECD Journal on Budgeting, Paris: OECD, v. 7, n. 1, 2007, p. 16-17.

${ }^{88}$ CURRISTINE, T. Governance performance: lessons and challenges. OECD Journal on Budgeting, Paris: OECD, v. 5, n. 1, 2005, p. 137. "The introduction of output and/or outcome targets as a system of management control requires relaxed input controls in order to give managers the freedom to use resources to achieve results and improve performance". 
Apesar disso, Curristine relata que não há grandes evidências de que isso tenha sido atingido na prática, com grandes variações entre os países.

Os Estados Unidos da América, por exemplo, não adotam em grande grau a flexibilização dos controles de insumos, enquanto países como Austrália e Holanda possuem controles mais relaxados. De todo modo, é relevante que se tenha uma flexibilidade mínima permitindo que os agentes possam atingir os resultados, pois se os meios para atingi-los forem controlados em sua totalidade, a conduta da administração estará completamente petrificada e inapta a criar mudanças.

Isto também se aplica na formação dos indicadores de desempenho. Não parece adequado que tais indicadores venham a ser instituídos de maneira excessivamente hierárquica. Os gestores, organizações e agências submetidos aos indicadores devem ter também participação ativa e iniciativa para indicar os seus próprios indicadores a serem utilizados, de maneira a ter maior envolvimento e aceitação nestes indicadores.

Parece principal compreender aqui que a administração burocrática baseada em comandos hierárquicos superiores é ineficaz para solucionar o problema do desempenho e eficiência do setor público.

Impõe-se a constituição de arranjos multilaterais com maior flexibilidade administrativa e financeira às entidades, que pode ser instituída com soluções jurídicas, inclusive contratuais, com o fim de criar compromissos na Administração Pública em torno do desempenho.

Trata-se de envolver os setores da Administração Pública como um todo a favor da realização de objetivos, desconstituindo amarras tradicionais dos mecanismos de exercício do poder.

Busca-se colaboração ativa de todos os atores envolvidos no processo de realização da atividade pública, e não somente o cumprimento formal de regras, exigências e ordens.

Para isso, o fortalecimento da liberdade de meios, administrativa e financeira, parece crucial ferramenta de trabalho a fim de alcançar os desideratos constitucionais sob a ótica do orçamento por resultados e da incorporação de critérios de desempenho na atividade financeira do Estado. 